\title{
Quantitative determination of the lowest density domain in major fault zones via medical X-ray computed tomography
}

Akiyuki Iwamori ${ }^{1,2^{*}}$ (D, Hideo Takagi ${ }^{3}$, Nobutaka Asahi ${ }^{4}$, Tatsuji Sugimori ${ }^{4}$, Eiji Nakata ${ }^{5}$, Shintaro Nohara ${ }^{5}$ and Keiichi Ueta ${ }^{5}$

\begin{abstract}
Determination of the youngest active domains in fault zones that are not overlain by Quaternary sedimentary cover is critical for evaluating recent fault activity, determining the current local stress field, and mitigating the impacts of future earthquakes. Considering the exhumation of a fault zone, the youngest active domain in a fault zone is supposed to correspond to the activity at the minimum fault depth of a buried fault, such that the most vulnerable area, which possesses the lowest rock/protolith density ratio, is assumed to be indicative of this recent fault activity. However, it is difficult to measure the density of fault rocks and map the rock/protolith density ratio across a given fault zone. Here, we utilize medical X-ray computed tomography (CT), a non-destructive technique for observing and analyzing materials, to investigate the fault characteristics of several fault zones and their surrounding regions in Japan, and attempt to determine the lowest density domain of a given fault zone based on its CT numbers, which are a function of the density and effective atomic number of the fault rock and protolith. We first investigate the density, void ratio, and effective atomic number of active and inactive fault rocks, and their respective protoliths. We then calculate the CT numbers after reducing the beam-hardening effects on the rock samples and study the relationships among the CT number, density, and effective atomic number. We demonstrate that the density, effective atomic number, and $\mathrm{CT}$ number of the fault rock decrease as the youngest active zone, identified by outcrop observation, are approached, such that the region with the lowest $C T$ number and rock/protolith density ratio defines the lowest density domain of a given fault zone. We also discuss the relationship between the lowest density domain and the youngest active domain in major fault zones and investigate the points to be considered when the youngest active domain is identified from the lowest density domain determined by the CT number.
\end{abstract}

Keywords: Medical X-ray CT, CT number, Beam hardening, Bulk density, Effective atomic number, Rock/protolith density ratio, The lowest density domain of a fault zone, The youngest active domain of a fault zone

\footnotetext{
* Correspondence: iwamori.akiyuki@d5.kepco.co.jp

${ }^{1}$ Kansai Electric Power Co. Inc., 3-6-16, Nakanoshima, Kita-ku, Osaka 530-8270,

Japan

${ }^{2}$ School of Creative Science and Engineering, Waseda University, 1-6-1,

Nishiwaseda, Shinjuku-ku, Tokyo 169-8050, Japan

Full list of author information is available at the end of the article
}

\section{Springer Open}

(c) The Author(s). 2021 Open Access This article is licensed under a Creative Commons Attribution 4.0 International License, which permits use, sharing, adaptation, distribution and reproduction in any medium or format, as long as you give appropriate credit to the original author(s) and the source, provide a link to the Creative Commons licence, and indicate if changes were made. The images or other third party material in this article are included in the article's Creative Commons licence, unless indicated otherwise in a credit line to the material. If material is not included in the article's Creative Commons licence and your intended use is not permitted by statutory regulation or exceeds the permitted use, you will need to obtain permission directly from the copyright holder. To view a copy of this licence, visit http://creativecommons.org/licenses/by/4.0/. 


\section{Introduction}

Determination of the youngest active domain in fault zones that are not overlain by Quaternary cover is integral not only for evaluating fault activity and restoring the most recent stress field using slip data but also for proposing local/regional earthquake disaster mitigation measures. Various methods have been employed to potentially determine the youngest active domain in fault zones in bedrock (e.g., Mizoguchi and Ueta 2012; Shigematsu et al. 2017; Tanaka et al. 2018). Considering the exhumation of a fault zone, this youngest active domain in a fault zone is supposed to correspond to the activity at the minimum fault depth of a buried fault, such that this most vulnerable area is assumed to be the area that possesses the lowest rock/protolith density ratio. Previous studies have focused on the density of the rocks around the fault zone (e.g., Morrow and Lockner 2001; Takeuchi et al. 2005); however, a quantitative density-based classification of fault rocks has not been performed to date. Rempe et al. (2013) combined seismic refraction tomography and microstructural observations of the fault rocks along the San Andreas Fault to estimate the effect of density reduction as a factor for the increase in compressional-wave velocity as the main fault plane is approached. Ikeda et al. (2001) performed geophysical well logging in the borehole through the Nojima Fault Zone, which was active during the 1995 Hyogo-ken Nanbu Earthquake, and reported that the non-fractured granite and the fault zone densities were $2.6-2.7$ and $1.5-2.5 \mathrm{~g} / \mathrm{cm}^{3}$, respectively. However, it is difficult to measure the density of fault rocks without being affected by disturbance because fault rock samples are very fragile. Here, we utilize medical X-ray computed tomography $(\mathrm{CT})$ to quantitatively determine the lowest density domain in each fault zone based on its CT numbers.

$\mathrm{X}$-ray $\mathrm{CT}$ is a non-destructive technique that images the three-dimensional (3D) internal structure of materials continuously in a short time. The potential of X-ray CT in geoscience was recognized soon after its development as a medical imaging technique in 1972 (Hounsfield 1973), resulting in numerous geoscience applications since the 1980s (e.g., Wellington and Vinegar 1987; Raynaud et al. 1989; Orsi et al. 1994; Boespflug et al. 1995; Verhelst et al. 1996; Geet et al. 2000; Ueta et al. 2000). Hirono et al. (2008) used X-ray CT to analyze the fault rocks generated during the 1999 ChiChi earthquake; however, they were unable to report on the relationship between the $\mathrm{CT}$ number and fault rock density, owing to the beam hardening $(\mathrm{BH})$ effect. Aiyama et al. (2017) recently observed the internal structure of a fault fracture zone using medical X-ray CT and reported that the $\mathrm{CT}$ image of the fault gouge zone was darker and less dense than that of the surrounding cataclasite.
$\mathrm{X}$-ray CT is generally conducted using either industrial- or medical-grade scanners. Industrial scanners employ high-energy $\mathrm{X}$-rays and are used to examine dense rocks or minerals. Medical scanners can also be employed in a geoscience context to study lowdensity, unconsolidated sediments (Nishizawa et al. 1995). Medical scanners are easier to operate than industrial scanners, but the resulting CT images, which are obtained at lower X-ray intensities, include artifacts, such as BH (Ketchman and Carlson 2001). Nakano et al. (2000) observed and analyzed the internal structures of lake sediment, basalt, and granite samples using a medical scanner after accounting for $\mathrm{X}$-ray attenuation and reducing the $\mathrm{BH}$ effect. However, the applicability of their methodology is not straightforward because a priori knowledge of the $\mathrm{X}$ ray spectrum of the scanner is required. Ketchman and Hanna (2014) and Geet et al. (2000) investigated the use of micro-CT in reducing the $\mathrm{BH}$ effects. Geet et al. (2000) estimated the density and effective atomic number via the dual-energy method, which uses CT images acquired at two different tube voltages; this approach is used to discriminate materials by focusing on changes in the contrast of the CT images due to the X-ray energy differences of the imaged materials.

Iwamori et al. (2020) investigated six different mineral samples with known densities and effective atomic numbers using medical CT images, and defined the CT values for these minerals, thereby providing an effective way to reduce the $\mathrm{BH}$ effect. Iwamori et al. (2020) also presented a method for determining the density and effective atomic number via the dual-energy method, and a method for estimating the density and effective atomic number using CT images taken with one tube voltage.

Here, we present a method to determine the lowest density domain in major fault zones using medical X-ray CT characteristics on the fault rock densities and effective atomic numbers. We first investigate the density, void ratio, and effective atomic number of active and inactive fault rocks, and their respective protoliths. We then calculate the CT numbers from CT images where the $\mathrm{BH}$ effects have been reduced and study the relationship among the CT number, density, and effective atomic number. We also discuss the relationship between the lowest density domain and youngest active domain in major fault zones and investigate the points to be considered when the youngest active domain is identified from the lowest density domain determined by the CT number. We reduce the effects of sample thickness variations and CT image quality deterioration due to the $\mathrm{X}$-ray energy reduction by adjusting the sample size and imaging direction based on $\mathrm{a} \sim 10 \mathrm{~cm} \mathrm{X}$-ray transmission thickness. 


\section{Geological structural characteristics and rock structural properties of each analyzed fault}

We analyzed three faults, the Median Tectonic Line (MTL), and the Yamada and Tsuruga faults, for our medical X-ray CT analysis. We chose the MTL since it is one of the longest onshore faults in Japan, with both active and inactive fault outcrops; the protoliths of the fault rocks consist mainly of Sanbagawa schists and Ryoke tonalites. We chose the Yamada Fault as an example of an active fault in granite, and the Tsuruga Fault as an example of an active fault at the geological boundary between metabasalt and granite. We focused on the fault rocks in the basement rock since the fault rock characteristics of the basement rock and basement rock-sediment contact zone are thought to be different. The sample details are provided in Table 1, with the geological outline of the study region and detailed geological maps of the investigated faults shown in Figs. 1 and 2, respectively. Here, we define an "active fault" as a fault that has been active since the late Pleistocene, and an "inactive fault" as a fault that has no recorded activity since the late Pleistocene.

\subsection{MTL in the Ina area, Nagano Prefecture (Hiji outcrop; active fault)}

The MTL is the longest onshore fault and extends across the central part of southwestern Japan for more than $1000 \mathrm{~km}$ (e.g., Okada 1992). The MTL is an approximately $\mathrm{N}-\mathrm{S}$-trending, vertically dipping feature in the Ina area of Nagano Prefecture (Fig. 2a). Mylonitic rocks that originated from Hiji tonalite are distributed within $\sim 1 \mathrm{~km}$ of the western side of the MTL in this area, with increasing grain-size reduction and alteration closer to the MTL; however, fault breccia and fault gouge are scarcely observed (Takagi 1984). Conversely, the Sanbagawa schist on the eastern side of the MTL is clayey and/or contains fractured lenticular bodies within a few meters of the MTL, with minimal macroscopic fractures $10-20 \mathrm{~m}$ from the MTL (Takagi 1984).

The Hiji outcrop $\left(35.80278^{\circ} \mathrm{N}, 138.08278^{\circ} \mathrm{E}\right)$ is located under a playground on the eastern bank of
Lake Miwa, a dammed reservoir in the Ina area. The MTL, which forms the boundary between the Hiji tonalite and the Sanbagawa schist (Fig. 3a), is clearly exposed, except in spring when the reservoir is full. The fault is located $\sim 80 \mathrm{~cm}$ east of the MTL in this outcrop, where it cuts a $<100$ ka terrace gravel deposit, and extends into the Sanbagawa schist without being displaced by other foliations (Takagi et al. 2019). The strike and dip of the latest fault plane $Y$ are $\mathrm{N} 3 \mathrm{E}$ and $74 \mathrm{~W}$, respectively, and the observed striations on the slip plane possess a rake of $20-30 \mathrm{~N}$ (Fig. 3a). The fault gouge zone along fault plane $Y$ clearly shows a dextral sense of shear (Fig. 3a, b). The observed displacement of $60 \mathrm{~cm}$ at the base of the terrace gravel deposit due to fault plane $Y$ equates to a real displacement velocity of $0.012-0.0118 \mathrm{~m} / \mathrm{ky}$ along this fault, assuming the gravel layer was deposited 100,000 years ago (Takagi et al. 2019).

Sample HJ-8, which was derived from the Sanbagawa pelitic schist, was taken from the fault zone that formed during the most recent fault activity identified as an extension of the latest active plane $Y$ described above at the Hiji outcrop. This fault rock sample (Fig. 3b) can be divided into five zones based on their degree of cohesiveness and the classification of Takagi and Kobayashi (1996). Zones HJ8-2-HJ8-4 are classified as fault gouges, whereas zones HJ8-1 and HJ8-5 are cataclasites; the boundary between zones HJ8-2 and HJ8-3 is defined by the main fault plane $Y$, which cuts the terrace gravel deposit (Fig. 3b).

Protolith sample MZ-5 was collected from an outcrop $\left(35.79150^{\circ} \mathrm{N}, 138.08269^{\circ} \mathrm{E}\right)$ located $\sim 20 \mathrm{~m}$ east of the Mizoguchi outcrop (1.2 km south of the Hiji outcrop), which is where the MTL crops out; this sample was selected for comparison with the fault rocks.

Photomicrographs of the fault rocks are shown in Fig. 3c, d. The cataclasite zone (HJ8-1) contains mainly $\leq 1 \mathrm{~mm}$ diameter quartz and albite fragments, with a dextral sense of slip observed. Fine-grained clay minerals are distributed uniformly in the fault gouge zone (HJ8-3), which is adjacent to fault plane $Y$, with a dextral sense of slip indicated. Sample MZ5 consists mainly of quartz, albite, phengite, calcite, and chlorite.

Table 1 Locations and fault/protolith details of the analyzed samples (see Figs. 1 and 2 for sample locations)

\begin{tabular}{|c|c|c|c|c|c|c|}
\hline \multirow[t]{2}{*}{ Fault } & \multirow[t]{2}{*}{ Location } & \multicolumn{2}{|l|}{ Sample } & \multirow[t]{2}{*}{ Protolith } & \multicolumn{2}{|c|}{ Fault activity classification } \\
\hline & & Fault rock & Protolith & & Active & Inactive \\
\hline \multirow[t]{2}{*}{ MTL } & Hiji & $\mathrm{HJ}-8$ & $M Z-5$ & schist & $\circ$ & - \\
\hline & Awano-Tabiki & AT, ATR-2,3,4 & ATS-1, 2, HA-1 & tonalite,schist & - & $\circ$ \\
\hline Tsuruga & Oritodani & $\mathrm{T}-3, \mathrm{C}-1, \mathrm{C}-2$ & $\mathrm{~K}-1, \mathrm{~T}-5$ & granite,metabasalt (greenstone) & $\circ$ & - \\
\hline Yamada & Mushu & YDA & YK-1 & granite & $\circ$ & - \\
\hline
\end{tabular}




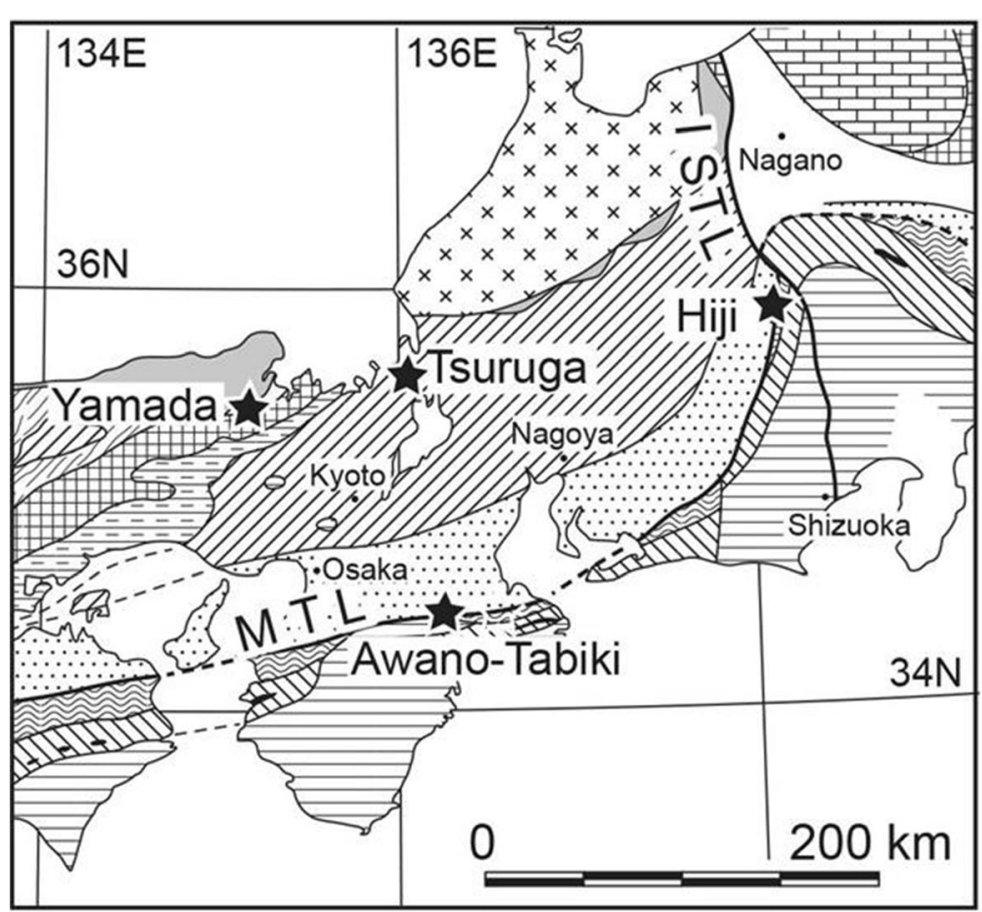

$x_{x}^{x} \times$ Hida-Oki Belt

Hida-gaien Belt

Akiyoshi Belt

Suo-Chizu Belt

Maizuru Belt

Ultra-Tanba Belt
Mino-Tanba Belt

Ryoke met. Belt

Sanbagawa met. Belt

Chichibu Belt

Kurosegawa Terrane

Shimanto Belt

\section{MTL :Median Tectonic Line \\ ISTL: Itoigawa-Shiziuoka Tectonic Line \\ met. : metamorphic}

Fig. 1 Simplified geotectonic map showing the location of the study area around the MTL and the Tsuruga and Yamada faults. The stars denote the approximate locations where the samples were collected (see Fig. 2 for further details on each sample site)

\subsection{MTL in the Matsusaka area, Mie Prefecture (Awano-} Tabiki outcrop; inactive fault)

The MTL is an approximately E-W-trending feature in the Matsusaka area of Mie Prefecture (Nishioka et al. 2010; Fig. 2b) that does not disrupt lower river terrace deposits, which means that there has been no known activity during the late Quaternary (Okada 1992). The Hatai tonalite is distributed within $2 \mathrm{~km}$ of the northern side of the MTL in this area and consists mainly of plagioclase, hornblende, and chloritized biotite. The Hatai tonalite is affected by mylonitization along the MTL and contains foliations that are almost parallel to the MTL (Takagi 1985).
The Awano-Tabiki outcrop (34.44294 N, $136.25292^{\circ}$ E) is located in Awano and Tabiki, Matsusaka City, Mie Prefecture. This outcrop comprises Ryoke Hatai tonalite and Sanbagawa schist (Fig. 3e). The Hatai tonalite consists of weathered, light-brown fault rocks with irregular but well-developed cracks and scarcely observed fault breccia and fault gouge in the Ryoke Belt. Conversely, the Sanbagawa schist is partly clayey and shows a dextral sense of shear within $2 \mathrm{~m}$ of the MTL, with minimal macroscopic fractures10-20 $\mathrm{m}$ from the MTL.

Shigematsu et al. (2017) reported that four stages of deformation have been recorded in the fault zone at this 


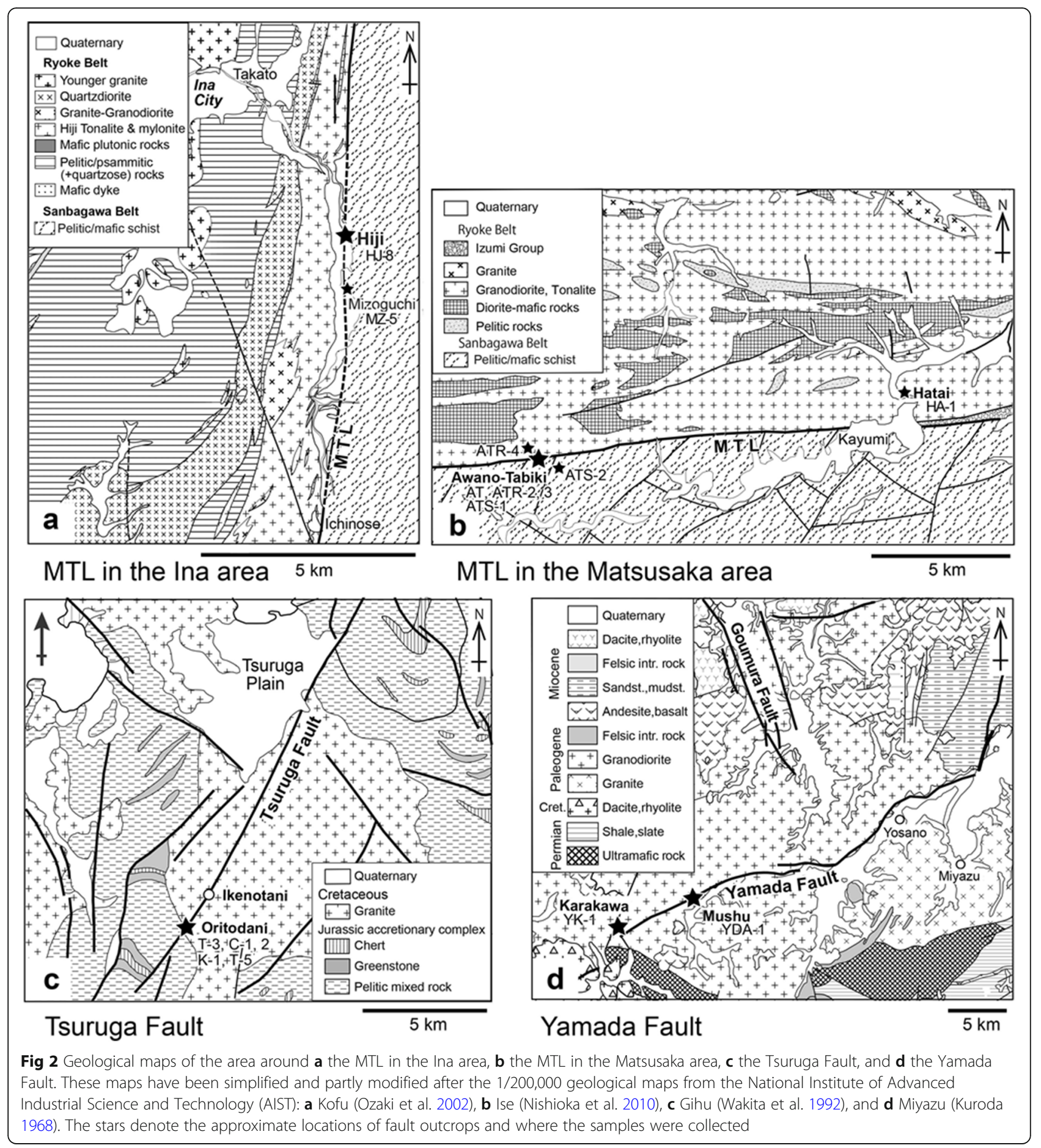

outcrop since the Paleocene, with the final stage consisting of Miocene-age normal faulting. Here, we investigated faults on the boundary between the Ryoke and Sanbagawa belts, with a focus on one of the two faults that Shigematsu et al. (2017) evaluated as possessing the youngest active domain.

The fault on the boundary between the Ryoke and Sanbagawa belts shows good continuity throughout the outcrop and is not disrupted by other faults. The most recent fault plane strikes N76E and dips $31 \mathrm{~N}$, with the striations on the slip plane possessing a rake of $88 \mathrm{NNW}$. The fault gouge zone $(1-3 \mathrm{~cm}$ wide) along this fault shows a normal sense of shear, which is consistent with the observed features that Shigematsu et al. (2017) identified as the final stage of deformation (Fig. 3e, f). 

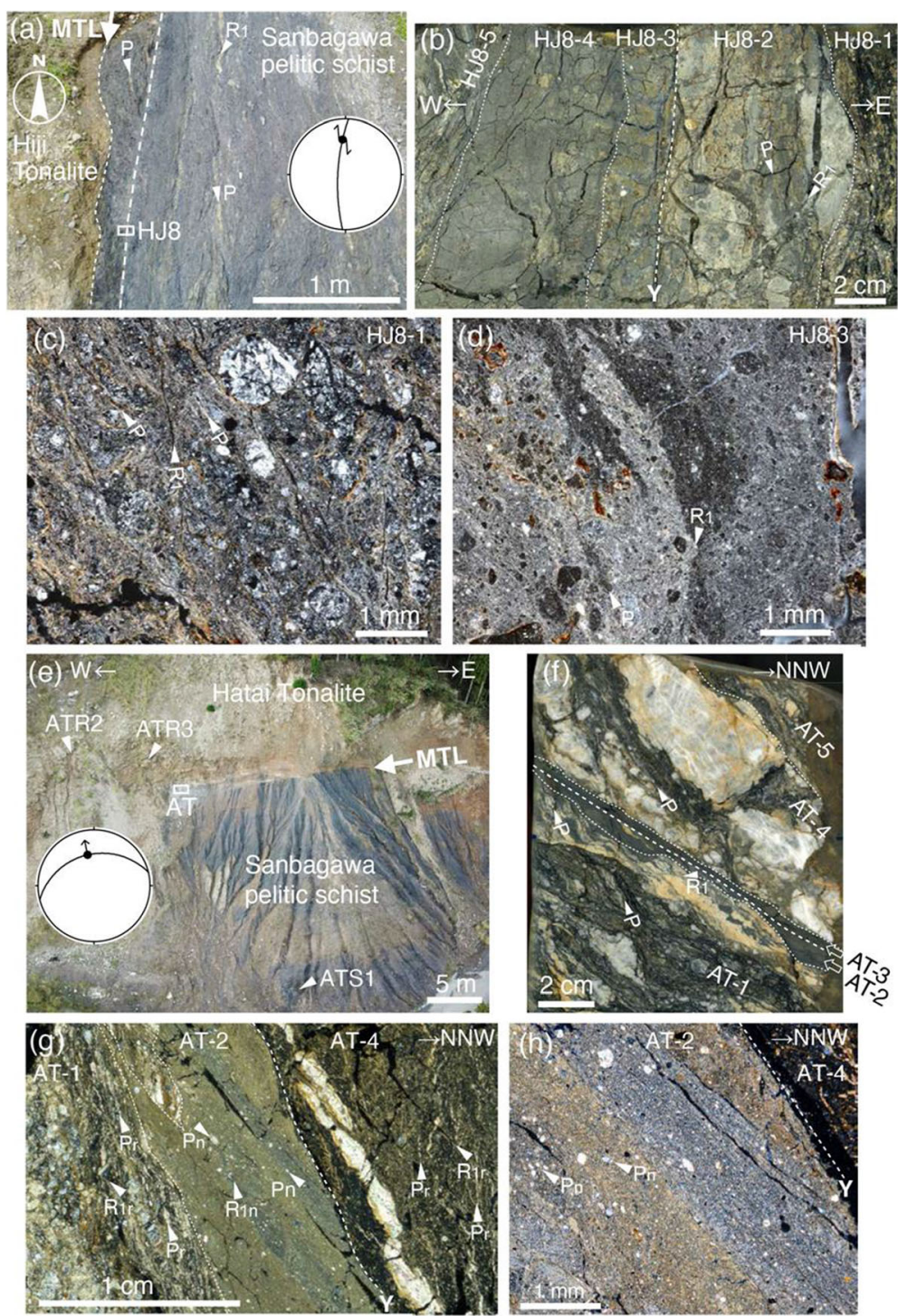

Fig. 3 Photographs of the outcrop ( $\mathbf{a}, \mathbf{e})$, and polished slab ( $\mathbf{b}, \mathbf{f})$ of the observed brittle fault rocks taken perpendicular to the fault plane and parallel to the lineations, and photomicrographs ( $\mathbf{c}, \mathbf{d}, \mathbf{g}, \mathbf{h}$; cross-polarized light) of the fault rock samples. a The Hiji outcrop of the MTL. $\mathbf{b}$ HJ8. $\mathbf{c}$ HJ8-1. d HJ8-3. e The Awano-Tabiki outcrop of the MTL. $\mathbf{f}$ AT. $\mathbf{g}$ AT-1-AT-2-AT-4. $\mathbf{h}$ AT-2-AT-4. The stereoplots show the orientation of fault plane $Y$ and the direction of slip in the zone formed during the most recent fault movements $(\mathbf{a}, \mathbf{e})$. Abbreviations in $(\mathbf{g})$ and $(\mathbf{h}): P: P$ foliation; $R_{1}$ : Riedel shear; $P_{\mathrm{n}}, P_{\mathrm{r}}$ : $P$ foliations showing normal and reverse senses of shear, respectively; $R_{1 \mathrm{n}}$, $R_{1}$ : Riedel shear showing normal and reverse senses of shear, respectively

Sample AT was taken from the fault zone that formed during the most recent fault movement on the geological boundary at this outcrop (Fig. 3f). This fault rock sample can be divided into five zones, based on their degree of cohesiveness: AT-2 and AT- 3 are fault gouges, and AT$1, \mathrm{AT}-4$, and AT- 5 are cataclasites. AT- 1 and AT- 2 correspond to the Sanbagawa Belt, and zones AT-3, AT-4, and AT-5 correspond to the Ryoke Belt, with the boundary between AT-2 and AT-3 representing the main fault plane $(Y)$ of the geological MTL boundary.

We collected four rock samples from the Ryoke Belt (ATR and HA samples) and two rock samples from the
Sanbagawa Belt (ATS samples) for analysis. Cataclasite samples ATR-2 and ATR-3 were collected $\sim 5 \mathrm{~m}$ to the north of the MTL (Fig. 3e), mylonite sample ATR-4 was collected $300 \mathrm{~m}$ to the north of the MTL (Fig. 2b), and protolith sample HA-1 was collected $13.5 \mathrm{~km}$ ENE of the outcrop (Fig. 2b) to provide a comparison of the fault rock and protolith characteristics with different degrees of cohesiveness. Protolith samples ATS-1 (20 m to the south of the MTL) and ATS-2 (550 m to the south of the MTL) were collected from the Sanbagawa Belt (Figs. 3c and 2b). ATS-2 is a solid pelitic schist with well-developed schistosity, whereas ATS-1 contains 2 
$\mathrm{cm}$ diameter quartz crystals. The cataclasite samples from the Hatai tonalite were analyzed using X-ray CT imaging (ATR-2) and density and X-ray fluorescence (XRF) analyses (ATR-3).

Photomicrographs of the fault rocks are shown in Fig. 3g, h. The thin AT section can be divided into three zones, AT-1, AT-2, and AT-4, with the latest fault plane $Y$ extending through the section without being displaced by other foliations. Zone AT-1, which consists of a Sanbagawa cataclasite, mainly contains $\leq 0.2 \mathrm{~mm}$ diameter albite fragments and shows a reverse sense of shear. Zone AT-4, which consists of a Ryoke cataclasite, contains $\leq 0.5 \mathrm{~mm}$ diameter mylonitized quartz fragments that have been affected by cataclastic flow and $0.2 \mathrm{~mm}$ wide calcite veins that have been displaced by a reverse sense of Riedel shearing. Fine-grained clay minerals are uniformly distributed throughout the fault gouge in zone AT-2, with a normal sense of slip indicated.

ATS-2, which is a Sanbagawa schist protolith, consists mainly of fine quartz, albite, phengite, and calcite crystals $(\leq 0.2 \mathrm{~mm}$ diameter crystals), and ATS- 1 contains mainly $\leq 0.2 \mathrm{~mm}$ diameter quartz, albite, phengite, and graphite fragments. ATS-2 contains less phengite than ATS-1, and the schistosities of both samples are regulated by the arrangement of the quartz and albite aggregates and/or phengite.

Samples HA-1 and ATR-4 consist mainly of quartz, plagioclase, hornblende, and chlorite. HA-1 contains $\leq 2 \mathrm{~mm}$ diameter plagioclase and amphibole crystals and $\leq 0.5 \mathrm{~mm}$ diameter quartz and chlorite crystals. Conversely, the mylonite ATR-4 sample contains $\leq 1 \mathrm{~mm}$ diameter plagioclase and hornblende crystals, and voids that are filled with recrystallized quartz aggregates. The cataclasite ATR-3 sample consists mainly of $\leq 0.2 \mathrm{~mm}$ diameter plagioclase, quartz, and chlorite crystals and mylonitized quartz fragments that have been affected by cataclastic flow.

\subsection{Tsuruga Fault (Oritodani outcrop; active fault)}

The Tsuruga Fault is a $\sim 25 \mathrm{~km}$ long, NE-SW-trending, right-lateral strike-slip fault in the central Fukui Prefecture (National Institute of Advanced Industrial Science and Technology 2016). Koujaku granite (Upper Cretaceous) and metabasalt (Middle-Upper Jurassic accretionary complex) from the Mino-Tanba Belt occur around this fault (Fig. 2c). Kurimoto et al. (1999) performed a trench excavation in the Ikenotani area and reported that the southern part of the Tsuruga Fault was active between the latter half of the twelfth and end of the fourteenth centuries, with a vertical displacement of $1.5-2 \mathrm{~m}$ and average vertical displacement velocity of $0.5-0.6 \mathrm{~m} / 10^{3}$ years.
The Oritodani outcrop $\left(35.53750^{\circ} \mathrm{N}, 136.01906^{\circ} \mathrm{E}\right)$, which is located $1.7 \mathrm{~km}$ southwest of the Ikenotani area, contains exposures of Koujaku granite and metabasalt, with a $10-20 \mathrm{~cm}$ wide fault gouge distributed along the geological boundary (Fig. 4a). The boundary fault between the granite and metabasalt is continuous throughout the outcrop and cuts the terrace gravel deposit. The strike and dip of the most recent fault plane are N49E and $78 \mathrm{~W}$, respectively, with the striations on the slip plane possessing a rake of $15 \mathrm{~N}$. A very soft fault gouge (T-3-3 zone), which is in contact with the main fault plane $Y$, is developed in the metabasalt along its boundary with the granite fault gouge (T-3-2 zone) and shows a dextral sense of shear (Fig. 4b, e).

Sample T-3 was taken from the fault zone, involving T-3-3 described above, that formed during the most recent fault activity at the Oritodani outcrop. This fault rock sample (Fig. 4b) can be divided into four zones based on their degree of cohesiveness: T-3-1, T-3-2, and $\mathrm{T}-3-3$ are fault gouges, and T-3-4 is a cataclasite. T-3-1 and T-3-2 correspond to the Koujaku granite, and T-3-3 and $\mathrm{T}-3-4$ correspond to the metabasalt, with the main fault plane $(Y)$ of the Tsuruga Fault extending through $\mathrm{T}-3-3$. The brown (T-3-1) and white (T-3-2) fault gouge zones are slightly harder than the T-3-3 zone, with the $P$ foliations in T-3-2 that have developed near the boundary with T-3-1 exhibiting a dextral sense of slip (Fig. 4b), which indicates that the zone up to $10 \mathrm{~cm}$ from the main fault plane was possibly affected by the most recent fault activity.

We collected cataclasite samples $\mathrm{C}-2$ and $\mathrm{C}-3$ and protolith sample $\mathrm{K}-1$ from the Koujaku granite at the Oritodani outcrop to compare the degrees of cohesiveness in the samples. We also collected cataclasite sample C-1 and protolith sample T-5 from the metabasalt of the Mino-Tanba Belt.

Photomicrographs of the fault rocks are shown in Fig. 4c-e. The latest fault plane $Y$ extends through T-3-3 without being displaced by other foliations. Fine-grained clay minerals are distributed uniformly throughout fault gouge T-3-3 and developed $P$ foliations with a dextral sense of slip are present. Conversely, fault gouge T-3-2 mainly contains $\leq 0.2 \mathrm{~mm}$ diameter quartz, K-feldspar, and plagioclase fragments and no clear fault plane (Fig. 4c, d). Therefore, the youngest activity of this fault is thought to have only been recorded in the most vulnerable fault gouge (T-3-3).

Protolith sample K-1 mainly consists of $\leq 3 \mathrm{~mm}$ diameter quartz, plagioclase, K-feldspar, and biotite crystals. Cataclasite sample $\mathrm{C}-2$ mainly consists of $\leq 0.3 \mathrm{~mm}$ diameter quartz, plagioclase, K-feldspar, and biotite crystals. Conversely, sample T- 5 mainly consists of $\leq 0.1 \mathrm{~mm}$ diameter hornblende and clinopyroxene crystals, whereas sample $\mathrm{C}-1$ 

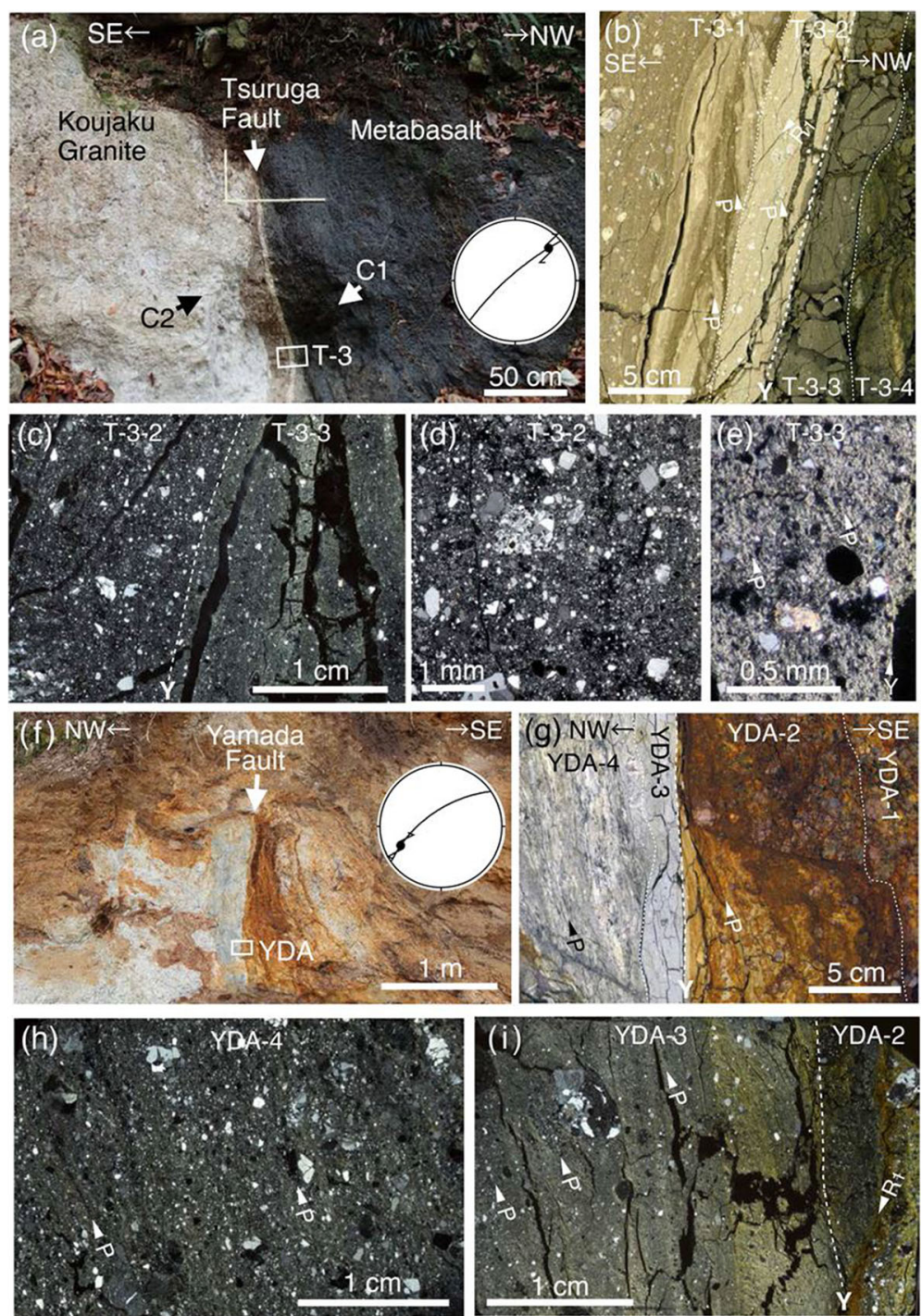

Fig. 4 Outcrop photographs $(\mathbf{a}, \mathbf{f})$, observed brittle fault rocks in the outcrops, photographs taken perpendicular to the fault plane and parallel to the lineations $(\mathbf{b}, \mathbf{g})$, and photomicrographs of the fault rock and protolith samples (c, $\mathbf{d}, \mathbf{e}, \mathbf{h}, \mathbf{i}$ : cross-polarized light). a The Oritodani outcrop of the Tsuruga Fault. b T-3. c T-3-2-T-3-3. d T-3-2. e T-3-3. f The Mushu outcrop of the Yamada Fault. g YDA. h YDA-4. i YDA-2-YDA-3. Stereoplots show the orientation of fault plane $Y$ and slip direction in the zone formed during the most recent fault movements $(\mathbf{a}, \mathbf{f})$. Abbreviations: P: P-

foliation; $R_{1}$ : Riedel shear

mainly consists of hornblende, chlorite, and plagioclase fragments, and fewer hornblende crystals than in sample T-5.

\subsection{Yamada Fault (Musyu outcrop; active fault)}

The Yamada Fault Zone is an ENE-WSW-trending dextral fault that forms the $\sim 33 \mathrm{~km}$ long Yamada Fault Zone at the base of the Tango Peninsula, northern Kyoto Prefecture (Earthquake Research Committee 2004). This fault zone is composed of the Yasukeyama, Yamada, and Koryuji faults; we hereafter identify the Yamada Fault Zone as the Yamada Fault. Miyazu granite (Upper Cretaceous-Paleogene) is present around the Yamada Fault (Fig. 2d).
The Mushu outcrop $\left(35.51722^{\circ} \mathrm{N}, 136.00797^{\circ} \mathrm{E}\right)$ contains a cataclasite zone of Miyazu granite and a fault with a $1-2 \mathrm{~cm}$ wide fault gouge that is continuous throughout the outcrop (Fig. 4f). The strike and dip of the latest fault plane are N55E and $62 \mathrm{~W}$, respectively, with striations on the slip plane possessing a rake of 20S. The fault gouge zone is very soft and shows a dextral sense of shear. Aiyama et al. (2017) investigated the activity of this fault in the Mushu outcrop and reported that the main fault plane, which has been active during the Quaternary, contains a fault gouge zone. Aiyama et al. (2017) also characterized this fault gouge zone as a layered structure with 
ten fault gouge layers that are indicative of repetitive activity after smectite crystallization. Iwamori et al. (2015) studied the activity of the Yamada Fault over the last $\sim 200,000$ years based on the faults that cut the sedimentary layer above the Mushu outcrop, and reported that the youngest fault activity occurred between 2000 and 200 years B.P.

Sample YDA was taken from the fault zone that formed during the most recent fault activity, which is an extension of the latest active plane that cuts the Holocene sediments, at the Mushu outcrop (Fig. 4g). This fault rock sample can be divided into four zones based on their degree of cohesiveness: YDA-1 and YDA-2 are fault breccias, YDA-3 is a fault gouge, and YDA-4 is a cataclasite. The boundary between YDA-2 and YDA-3 represents the main fault plane $Y$, and the fault breccias are dark brown due to iron oxide deposition. We collected a Miyazu granite protolith sample (YK-1) at Karakawa, $\sim 6 \mathrm{~km}$ WSW of the Mushu outcrop (Fig. 2d), for comparison with the fault rocks.

Photomicrographs of the fault rocks are shown in Fig. 4h, i. The latest fault plane $Y$ extends along the boundary between the YDA-2 and YDA-3 fault gouge zones without being displaced by other foliations. YDA3 consists of a fine-grained clay mineral matrix that contains a mainly uniform distribution of $\leq 0.2 \mathrm{~mm}$ diameter quartz, K-feldspar, and plagioclase fragments, and possesses a $P$ foliation that indicates a dextral sense of slip. Conversely, fault breccia YDA-2 mainly consists of $\leq 0.3 \mathrm{~mm}$ diameter quartz, K-feldspar, plagioclase, and biotite fragments in a matrix of brown clay minerals. Cataclasite YDA-4 mainly consists of $\leq 0.2 \mathrm{~mm}$ diameter quartz, K-feldspar, plagioclase, and biotite fragments in a clay mineral matrix. Conversely, protolith sample YK-1 is mainly composed of quartz, plagioclase, K-feldspar, and biotite ( $\leq 5 \mathrm{~mm}$ diameter crystals).

\section{Density, porosity, and effective atomic number}

\subsection{Measurement method}

Different methods were employed to obtain density measurements for the protolith and fault rock samples since the fault rock samples generally contained many voids. The density analysis for the protolith samples was performed according to the standard Japanese test method for determining the bulk density of rocks (JGS2132-2009; The Japanese Geotechnical Society 2017). The densities of the fault rock samples were determined via mercury intrusion porosimetry (AutoPore IV 9500, Version 2.02; Micromeritics; Norcross, Georgia, USA) at the Central Research Institute of Electric Power Industry (CRIEPI; Abiko-shi, Chiba, Japan); this analysis also allowed an examination of the microcracks and pores within each sample.
The effective atomic number, $Z_{\mathrm{e}}$, of a compound consisting of multiple types of atoms is defined as:

$$
Z_{\mathrm{e}}=\left(\Sigma f_{i} Z_{i}^{3.8}\right)^{1 / 3.8}
$$

where $f_{i}$ is the fraction of electrons on the $i$ th atomic number species. For example, the effective atomic number of a crystal composed of one silicon atom $(Z=14)$ and two oxygen atoms $(Z=8)$ is $\left(14 / 30 \times 14^{3.8}+16 / 30\right.$ $\left.\times 8^{3.8}\right)^{1 / 3.8}=11.85$. Here we calculated the effective atomic number, $Z_{\text {et }}$, of each sample based on the contents of the main components $\left(\mathrm{SiO}_{2}, \mathrm{TiO}_{2}, \mathrm{Al}_{2} \mathrm{O}_{3}\right.$, $\mathrm{Fe}_{2} \mathrm{O}_{3}, \mathrm{MnO}, \mathrm{MgO}, \mathrm{CaO}, \mathrm{Na}_{2} \mathrm{O}, \mathrm{K}_{2} \mathrm{O}$, and $\mathrm{P}_{2} \mathrm{O}_{5}$ ), which were measured via XRF analysis. Fused glass bead samples underwent XRF analysis using a spectrometer at CRIEPI (XRF-1500, Rh X-ray tube; Shimadzu Co., Ltd; Nakagyo-ku, Kyoto, Japan) to obtain the $Z_{\text {et }}$ values.

\subsection{Measurement results}

The density, $\rho_{\mathrm{t}}$, porosity, $\phi$, and $Z_{\text {et }}$ measurement results are shown in Table 2 and Fig. 5, and Table 3 contains the XRF analysis results, which were used to calculate $Z_{\text {et }}$.

The $\rho_{\mathrm{t}}$ values of the rock samples decrease as it approaches the latest active plane $Y$ of each analyzed fault identified by the outcrop observation. (Fig. 5a). The mean $\rho_{\mathrm{t}}$ values are $2.69 \mathrm{~g} / \mathrm{cm}^{3}$ (standard deviation (SD) $\left.=0.10 \mathrm{~g} / \mathrm{cm}^{3}\right)$ for the protolith, $2.28 \mathrm{~g} / \mathrm{cm}^{3}(\mathrm{SD}=0.24 \mathrm{~g} /$ $\mathrm{cm}^{3}$ ) for the cataclasite, $2.16 \mathrm{~g} / \mathrm{cm}^{3}\left(\mathrm{SD}=0.21 \mathrm{~g} / \mathrm{cm}^{3}\right)$ for the fault gouge along the inactive faults, $1.92 \mathrm{~g} / \mathrm{cm}^{3}$ $\left(S D=0.16 \mathrm{~g} / \mathrm{cm}^{3}\right)$ for the fault gouge along the active faults, and $1.73 \mathrm{~g} / \mathrm{cm}^{3}$ (no SD calculated since there were only two samples) for the fault breccia (Table 2).There is an $\sim 24 \%$ increase in $\phi$ as $\rho_{\mathrm{t}}$ decreases by $1 \mathrm{~g} / \mathrm{cm}^{3}$, regardless of rock type (fault rock or protolith; Fig. 5b). The mean $\phi$ values are $1.5 \%(\mathrm{SD}=1.0 \%)$ for the protolith, $12.6 \%$ ( $\mathrm{SD}=6.9 \%$ ) for the cataclasite, $12.0 \%$ ( $\mathrm{SD}=$ $4.8 \%)$ for the fault gouge along the inactive faults, $17.4 \%$ $(\mathrm{SD}=4.6 \%)$ for the fault gouge along the active faults, and $32.2 \%$ for the fault breccia (Table 2). The fault gouge along active faults has a smaller density and larger porosity than the fault gouge along inactive faults. The average density and porosity of the three cataclasite samples located near the fault gouge along the inactive faults (AT-1, AT-4, and AT-5) are $2.44 \mathrm{~g} / \mathrm{cm}^{3}$ and $7.8 \%$, respectively, whereas those of the four cataclasite samples adjacent to the fault gouge along the active faults (HJ8-1, HJ8-5, T-3-4, and YDA-4) are $2.03 \mathrm{~g} / \mathrm{cm}^{3}$ and $19.7 \%$, respectively. Furthermore, the density of the fault rock samples increases and the porosity decreases with increasing distance from the latest active fault plane. For example, the average density and porosity of two cataclasite samples located $\sim 50 \mathrm{~cm}$ from 
Table 2 Density, porosity, and XRF analysis results

\begin{tabular}{|c|c|c|c|c|c|c|c|c|c|}
\hline \multirow[t]{2}{*}{$\begin{array}{l}\text { Fault } \\
\text { name }\end{array}$} & \multirow[t]{2}{*}{ Location } & \multirow[t]{2}{*}{ Material } & \multirow[t]{2}{*}{ Sample number } & \multirow{2}{*}{$\begin{array}{l}\text { Bulk density } \\
\rho_{\mathrm{t}}\end{array}$} & \multirow{2}{*}{$\begin{array}{l}\text { Porosity } \\
\varphi\end{array}$} & \multirow{2}{*}{$\begin{array}{l}\text { Effective atomic number } \\
Z_{\text {et }}\end{array}$} & \multicolumn{2}{|c|}{$\begin{array}{l}\text { Fault gouge } \\
\text { classification }\end{array}$} & \multirow[t]{2}{*}{ Protolith } \\
\hline & & & & & & & Active & Inactive & \\
\hline \multirow[t]{16}{*}{ MTL } & \multirow[t]{5}{*}{ Hiji } & Cataclasite & HJ8-1 & 2.03 & 19.5 & 12.30 & - & - & \multirow[t]{6}{*}{ schist } \\
\hline & & Fault gouge & HJ8-2 & 1.70 & 25.4 & 12.04 & $\circ$ & - & \\
\hline & & Fault gouge & HJ8-3 & 1.89 & 13.9 & 12.24 & $\circ$ & - & \\
\hline & & Fault gouge & HJ8-4 & 1.80 & 19.8 & 12.12 & $\circ$ & - & \\
\hline & & Cataclasite & HJ8-5 & 1.87 & 17.7 & 12.11 & - & - & \\
\hline & Mizoguchi & Protolith & $M Z-5$ & 2.77 & 1.2 & 12.38 & - & - & \\
\hline & \multirow[t]{10}{*}{ Awano-Tabiki } & Protolith & ATS-2 & 2.66 & 2.4 & 12.64 & - & - & \multirow[t]{4}{*}{ schist } \\
\hline & & & ATS-1 & 2.61 & 1.5 & 12.63 & - & - & \\
\hline & & Cataclasite & AT-1 & 2.26 & 14.4 & 11.34 & - & - & \\
\hline & & Fault gouge & AT-2 & 1.79 & 20.0 & 11.52 & - & $\circ$ & \\
\hline & & Fault gouge & AT-3 & 2.31 & 7.4 & 11.36 & - & $\circ$ & \multirow[t]{6}{*}{ tonalite } \\
\hline & & Cataclasite & AT-4 & 2.61 & 1.7 & 11.45 & - & - & \\
\hline & & Cataclasite & AT-5 & 2.44 & 7.4 & 11.42 & - & - & \\
\hline & & Cataclasite & ATR- $2,3^{*}$ & 2.56 & 3.3 & 12.17 & - & - & \\
\hline & & Mylonite & ATR-4 & 2.65 & 1.0 & 12.13 & - & - & \\
\hline & & Protolith & $\mathrm{HA}-1$ & 2.76 & 0.6 & 12.72 & - & - & \\
\hline \multirow[t]{9}{*}{ Tsuruga } & \multirow[t]{9}{*}{ Oritodani } & Protolith & K-1 & 2.58 & 0.3 & 12.16 & - & - & \multirow[t]{5}{*}{ granite } \\
\hline & & Cataclasite & $C-3$ & 2.47 & 4.6 & 12.11 & - & - & \\
\hline & & Cataclasite & $C-2$ & 2.16 & 16.1 & 12.10 & - & - & \\
\hline & & Fault gouge & $\mathrm{T}-3-1$ & 2.28 & 10.1 & 11.96 & - & $\circ$ & \\
\hline & & Fault gouge & $\mathrm{T}-3-2$ & 2.27 & 10.4 & 12.08 & - & $\circ$ & \\
\hline & & Fault gouge & $\mathrm{T}-3-3$ & 2.15 & 13.4 & 12.54 & $\circ$ & - & \multirow[t]{4}{*}{ metabasalt } \\
\hline & & Cataclasite & $\mathrm{T}-3-4$ & 2.23 & 18.9 & 13.55 & - & - & \\
\hline & & Cataclasite & $C-1$ & 2.43 & 12.4 & 14.10 & - & - & \\
\hline & & Protolith & $\mathrm{T}-5$ & 2.90 & 3.5 & 13.96 & - & - & \\
\hline \multirow[t]{5}{*}{ Yamada } & \multirow[t]{4}{*}{ Mushu } & Fault breccia & YDA-1 & 1.84 & 28.0 & 12.43 & - & - & \multirow[t]{5}{*}{ granite } \\
\hline & & Fault breccia & YDA-2 & 1.61 & 36.3 & 12.43 & - & - & \\
\hline & & Fault gouge & YDA-3 & 2.05 & 14.3 & 11.99 & $\circ$ & - & \\
\hline & & Cataclasite & YDA-4 & 1.98 & 22.7 & 12.05 & - & - & \\
\hline & Karakawa & Protolith & YK-1 & 2.61 & 1.7 & 12.45 & - & - & \\
\hline- & & Material & Number of samples & Bulk density & STD & Porosity & STD & $\begin{array}{l}\text { Fault activ } \\
\text { classificati }\end{array}$ & \\
\hline \multirow{5}{*}{\multicolumn{2}{|c|}{ Mean of all samples }} & Fault breccia & 2 & 1.73 & - & 32.2 & - & Active fau & \\
\hline & & Fault gouge & 5 & 1.92 & 0.16 & 17.4 & 4.6 & Active fau & \\
\hline & & Fault gouge & 4 & 2.16 & 0.21 & 12.0 & 4.8 & Inactive fa & ault \\
\hline & & Cataclasite & 11 & 2.28 & 0.24 & 12.6 & 6.9 & - & \\
\hline & & Protolith,Mylonite & 8 & 2.69 & 0.10 & 1.5 & 1.0 & - & \\
\hline
\end{tabular}

"ATR-2 was used for X-ray CT image analysis and ATR-3 was used for density and XRF analysis.

the latest active plane $Y(\mathrm{C}-1$ and $\mathrm{C}-2)$ are $2.30 \mathrm{~g} / \mathrm{cm}^{3}$ and $14.3 \%$, respectively, and those of a cataclasite sample located $\sim 20 \mathrm{~m}$ from the same fault plane $Y(\mathrm{C}-3)$ are $2.47 \mathrm{~g} / \mathrm{cm}^{3}$ and $4.6 \%$, respectively. The density and porosity of sample ATR-3, which is $\sim 3 \mathrm{~m}$ away from the youngest fault plane of an inactive fault, are $2.56 \mathrm{~g} / \mathrm{cm}^{3}$ and 3.3\%, respectively. Zhang et al. (2020) conducted an experimental study on the behavior of fault gouge under 


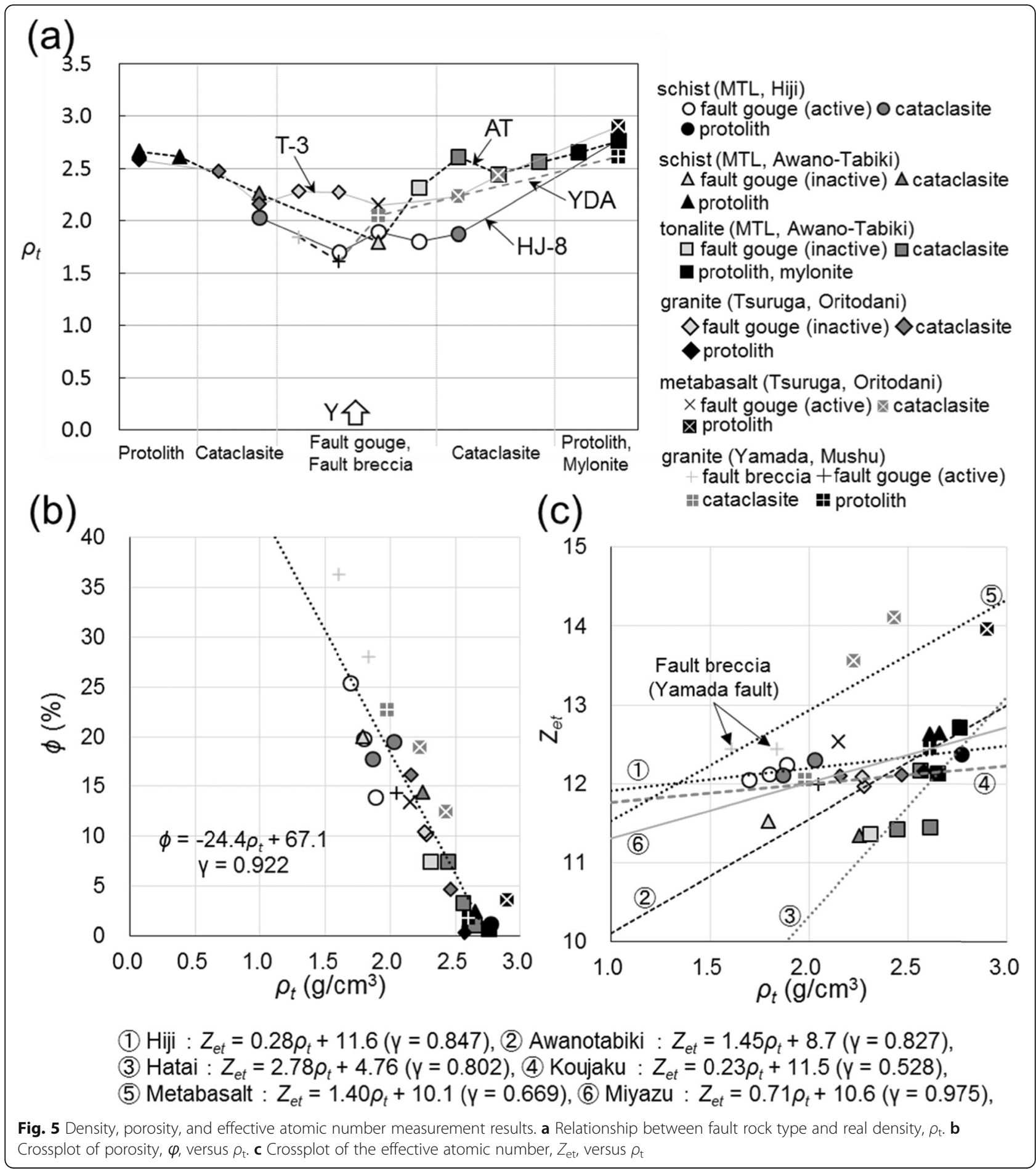

frictional shear to examine gouge dilation, frictional strength, stability, and healing, and reported that gouge dilation decreased with increasing normal stress. Therefore, the porosity of the fault gouge along the active faults is larger than that of the fault gouge along the inactive faults because the fault gouge along active faults forms at shallower depths and has a larger dilatancy than the fault gouge along inactive faults. For example, the average porosity of the cataclasite samples adjacent to the fault gouge along active faults ( $\mathrm{C}-1$ and $\mathrm{C}-2$; $14.3 \%)$ is larger than those of the cataclasite samples that are either distal from active faults (C-3; 4.6\%) or adjacent to the fault gouge along inactive faults (ATR-3; 3.3\%). 
Table 3 XRF analysis and effective atomic number $\left(Z_{e t}\right)$ results for the rock samples

\begin{tabular}{|c|c|c|c|c|c|c|c|c|c|c|c|c|c|c|c|c|}
\hline Faultname & Location & Material & $\begin{array}{l}\text { Sample } \\
\text { number }\end{array}$ & $\mathrm{SiO}_{2}$ & $\mathrm{TiO}_{2}$ & $\mathrm{Al}_{2} \mathrm{O}_{3}$ & $\mathrm{Fe}_{2} \mathrm{O}_{3}$ & $\mathrm{MnO}$ & $\mathrm{MgO}$ & $\mathrm{CaO}$ & $\mathrm{Na}_{2} \mathrm{O}$ & $\mathrm{K}_{2} \mathrm{O}$ & $\mathrm{P}_{2} \mathrm{O}_{5}$ & ig.loss ${ }^{*}$ & Total & $\begin{array}{l}\text { Effective } \\
\text { atomic } \\
\text { number } \\
\text { of rock } \\
\text { sample }\end{array}$ \\
\hline \multicolumn{4}{|c|}{ effective atomic number } & 11.85 & 19.13 & 11.34 & 23.56 & 23.26 & 10.87 & 18.36 & 10.42 & 18.11 & 12.37 & - & - & - \\
\hline \multirow[t]{16}{*}{ MTL } & \multirow[t]{5}{*}{ Hiji } & Cataclasite & HJ8-1 & 67.05 & 0.72 & 13.96 & 6.57 & 0.28 & 3.23 & 0.61 & 1.41 & 2.21 & 0.10 & 3.86 & 100.00 & 12.30 \\
\hline & & $\begin{array}{l}\text { Fault } \\
\text { gouge }\end{array}$ & HJ8-2 & 61.83 & 0.71 & 15.04 & 7.57 & 0.14 & 6.15 & 1.08 & 0.43 & 0.75 & 0.05 & 6.25 & 100.00 & 12.04 \\
\hline & & $\begin{array}{l}\text { Fault } \\
\text { gouge }\end{array}$ & HJ8-3 & 63.71 & 0.73 & 14.07 & 8.15 & 0.20 & 5.23 & 1.00 & 0.71 & 0.85 & 0.05 & 5.30 & 100.00 & 12.24 \\
\hline & & $\begin{array}{l}\text { Fault } \\
\text { gouge }\end{array}$ & HJ8-4 & 62.28 & 0.74 & 15.10 & 7.73 & 0.37 & 5.67 & 1.11 & 0.41 & 0.56 & 0.08 & 5.95 & 100.00 & 12.12 \\
\hline & & Cataclasite & HJ8-5 & 67.34 & 0.62 & 12.02 & 6.69 & 0.20 & 5.41 & 0.71 & 0.43 & 1.37 & 0.06 & 5.15 & 100.00 & 12.11 \\
\hline & Mizoguchi & Protolith & $M Z-5$ & 66.22 & 0.60 & 14.98 & 5.49 & 0.13 & 2.02 & 1.65 & 2.25 & 3.44 & 0.10 & 3.10 & 100.00 & 12.38 \\
\hline & \multirow{10}{*}{$\begin{array}{l}\text { Awano- } \\
\text { Tabiki }\end{array}$} & Protolith & ATS-2 & 64.95 & 0.70 & 17.10 & 6.16 & 0.19 & 2.05 & 0.93 & 2.62 & 3.80 & 0.18 & 1.33 & 100.00 & 12.64 \\
\hline & & & ATS-1 & 57.10 & 0.76 & 17.34 & 9.22 & 1.89 & 1.63 & 0.69 & 1.58 & 3.60 & 0.15 & 6.04 & 100.00 & 12.63 \\
\hline & & Cataclasite & AT-1 & 56.36 & 0.33 & 6.96 & 3.92 & 0.15 & 5.93 & 10.23 & 1.23 & 1.04 & 0.07 & 13.78 & 100.00 & 11.34 \\
\hline & & $\begin{array}{l}\text { Fault } \\
\text { gouge }\end{array}$ & AT-2 & 59.53 & 0.69 & 13.23 & 4.23 & 0.10 & 4.75 & 4.66 & 0.56 & 2.07 & 0.10 & 10.08 & 100.00 & 11.52 \\
\hline & & $\begin{array}{l}\text { Fault } \\
\text { gouge }\end{array}$ & AT-3 & 52.90 & 0.54 & 10.99 & 5.17 & 0.15 & 5.89 & 8.15 & 0.21 & 1.76 & 0.08 & 14.16 & 100.00 & 11.36 \\
\hline & & Cataclasite & AT-4 & 57.93 & 0.73 & 12.59 & 8.68 & 0.12 & 4.85 & 1.81 & 0.36 & 0.18 & 0.12 & 12.63 & 100.00 & 11.45 \\
\hline & & Cataclasite & AT-5 & 56.18 & 0.52 & 10.73 & 6.15 & 0.13 & 5.74 & 5.87 & 0.07 & 1.31 & 0.14 & 13.16 & 100.00 & 11.42 \\
\hline & & Cataclasite & ATR-2,3 & 70.28 & 0.68 & 15.72 & 3.98 & 0.06 & 0.60 & 0.36 & 2.86 & 2.91 & 0.14 & 2.41 & 100.00 & 12.17 \\
\hline & & Mylonite & ATR-4 & 65.44 & 0.52 & 16.05 & 3.97 & 0.07 & 1.42 & 3.50 & 3.33 & 1.90 & 0.10 & 3.70 & 100.00 & 12.13 \\
\hline & & Protolith & $\mathrm{HA}-1$ & 57.97 & 0.85 & 16.14 & 7.51 & 0.13 & 3.22 & 5.95 & 2.77 & 1.69 & 0.15 & 3.61 & 100.00 & 12.72 \\
\hline \multirow[t]{9}{*}{ Tsuruga } & \multirow[t]{9}{*}{ Oritodani } & Protolith & $\mathrm{K}-1$ & 76.87 & 0.07 & 12.63 & 1.26 & 0.04 & 0.07 & 0.42 & 3.59 & 4.64 & 0.01 & 0.39 & 100.00 & 12.16 \\
\hline & & Cataclasite & $C-3$ & 76.65 & 0.06 & 12.78 & 1.19 & 0.01 & 0.12 & 0.48 & 3.53 & 4.50 & 0.01 & 0.66 & 100.00 & 12.11 \\
\hline & & Cataclasite & $C-2$ & 77.48 & 0.05 & 12.03 & 0.87 & 0.02 & 0.15 & 0.84 & 2.88 & 4.74 & 0.01 & 0.92 & 100.00 & 12.10 \\
\hline & & $\begin{array}{l}\text { Fault } \\
\text { gouge }\end{array}$ & T-3-1 & 72.91 & 0.05 & 12.06 & 1.34 & 0.08 & 0.40 & 3.29 & 1.71 & 4.31 & 0.02 & 3.83 & 100.00 & 11.96 \\
\hline & & $\begin{array}{l}\text { Fault } \\
\text { gouge }\end{array}$ & T-3-2 & 76.48 & 0.05 & 12.69 & 1.64 & 0.01 & 0.43 & 0.52 & 2.12 & 4.49 & 0.02 & 1.57 & 100.00 & 12.08 \\
\hline & & $\begin{array}{l}\text { Fault } \\
\text { gouge }\end{array}$ & $T-3-3$ & 67.55 & 0.94 & 12.52 & 6.48 & 0.10 & 1.91 & 2.43 & 1.52 & 2.98 & 0.22 & 3.34 & 100.00 & 12.54 \\
\hline & & Cataclasite & $T-3-4$ & 55.34 & 3.21 & 11.60 & 14.02 & 0.26 & 4.37 & 4.15 & 1.37 & 1.37 & 0.59 & 3.72 & 100.00 & 13.55 \\
\hline & & Cataclasite & $C-1$ & 49.73 & 2.84 & 13.04 & 16.39 & 0.27 & 4.06 & 6.67 & 3.06 & 0.98 & 0.80 & 2.16 & 100.00 & 14.10 \\
\hline & & Protolith & $\mathrm{T}-5$ & 50.24 & 1.80 & 11.89 & 12.31 & 0.23 & 6.47 & 11.35 & 3.02 & 1.30 & 0.18 & 1.20 & 100.00 & 13.96 \\
\hline \multirow[t]{4}{*}{ Yamada } & \multirow[t]{3}{*}{ Mushu } & $\begin{array}{l}\text { Fault } \\
\text { breccia }\end{array}$ & YDA-1,2 & 70.22 & 0.37 & 14.70 & 4.28 & 0.12 & 0.37 & 1.09 & 3.20 & 4.13 & 0.08 & 1.45 & 100.00 & 12.43 \\
\hline & & $\begin{array}{l}\text { Fault } \\
\text { gouge }\end{array}$ & YDA-3 & 70.97 & 0.62 & 16.10 & 3.32 & 0.00 & 0.79 & 0.77 & 0.58 & 2.96 & 0.23 & 3.66 & 100.00 & 11.99 \\
\hline & & Cataclasite & YDA-4 & 74.45 & 0.29 & 14.51 & 1.52 & 0.01 & 0.46 & 0.81 & 2.12 & 4.07 & 0.08 & 1.67 & 100.00 & 12.05 \\
\hline & Karakawa & Protolith & YK-1 & 70.01 & 0.43 & 14.98 & 3.30 & 0.08 & 0.82 & 2.00 & 3.65 & 4.04 & 0.10 & 0.60 & 100.00 & 12.45 \\
\hline
\end{tabular}

${ }^{*}$ ig.loss indicates ignition loss of each sample

Every rock type yielded a positive correlation between $\rho_{\mathrm{t}}$ and $Z_{\mathrm{et}}$ (Fig. 5c), even though the $\rho_{\mathrm{t}}$ and $Z_{\mathrm{et}}$ are expected to vary among different rock types. Fault breccia YDA-1 and YDA-2 of the Yamada Fault both exhibit maximum $\rho_{\mathrm{t}}$ decreases of $\sim 40 \%$, whereas the $Z_{\text {et }}$ values are almost the same as that for protolith YK-1, which means that the relationship between $\rho_{\mathrm{t}}$ and $Z_{\text {et }}$ for the fault breccias is quite different from 
those of the other samples. This is because YDA-1 and YDA-2 have been strongly affected by weathering, as evidenced by their dark-brown color at outcrop and an $\mathrm{Fe}_{2} \mathrm{O}_{3}$ content of $4.28 \mathrm{wt} \%$, which is much higher than those of the fault gouge, cataclasite, and protolith samples (Table 3). Therefore, the fault breccia samples were excluded from the subsequent study of the $\rho_{\mathrm{t}}-Z_{\mathrm{et}}$ relationships among the collected rock samples.

\section{X-ray CT image analysis, and relationships among the $\mathrm{CT}$ number, density, and effective atomic number}

We conducted X-ray CT image analysis on the fault rock and protolith samples to determine how their CT values, which determine the degree of brightness of the CT image, may relate to $\rho_{\mathrm{t}}$ and $Z_{\mathrm{et}}$. We also attempted to quantitatively evaluate the characteristics of the fault rocks using CT values. We analyzed 28 samples, excluding the fault breccia samples (YDA-1 and YDA-2) because of their heterogeneity relative to the other samples.

\subsection{X-ray attenuation principle}

CT imaging captures the 3D X-ray attenuation distribution in a sample (e.g., Nakano et al. 2000; Tsuchiyama et al. 2000; Ketchman and Carlson 2001). The basic equation for the attenuation of a monoenergetic beam through a homogeneous material is given by Beer's Law:

$$
I=I_{0} \quad \exp (-\mu S)
$$

where $I_{0}$ is the initial intensity of the incident X-ray beam, $I$ is its emergent intensity, $S$ is the sample thickness, and $\mu$ is the linear X-ray attenuation coefficient (LAC) of the sample. The LAC depends on both bulk density, $\rho$, and the atomic number, $Z$ (Wellington and Vinegar 1987):

$$
\mu=\rho\left(a+b Z^{3.8} / E^{3.2}\right),
$$

where $E$ is the X-ray energy $(\mathrm{keV}), a$ is a nearly energy-independent coefficient this is termed the KleinNishina coefficient, and $b$ is a constant. Eq. (3) is applicable for monochromatic X-rays, such as those from a synchrotron radiation facility. However, this equation does not hold for most commercial X-ray CT scanners, which use polychromatic X-ray beams, because $\mu$ depends on the X-ray energy (e.g., Nakano et al. 2000; Tsuchiyama et al. 2000). The photoelectric absorption of a compound consisting of multiple types of atoms is proportional to the effective atomic number calculated via Eq. (1) (Wellington and Vinegar 1987).

The CT number, $N_{\mathrm{CT}}$, which determines the contrast of a CT image, is defined as:

$$
N_{\mathrm{CT}}=1000 \times\left(\mu-\mu_{\mathrm{w}}\right) / \mu_{\mathrm{w}},
$$

where $\mu_{\mathrm{w}}$ is the X-ray attenuation coefficient of pure water. A polychromatic X-ray CT scanner will allow $\mu$ to vary depending on the $\mathrm{X}$-ray energy (effective energy), as described above. The influence of the variations in $\mu$ with the energy differences in an X-ray energy distribution is reduced by calculating $N_{\mathrm{CT}}$, which is standardized using the $\mu$ ratio in Eq. (4). Substitution of Eq. (3) into Eq. (4) therefore highlights the dependence of $N_{\mathrm{CT}}$ on $\rho$ and $Z_{\mathrm{e}}$ when the tube voltage and X-ray effective energy of a medical scanner are held constant.

\subsection{CT image analysis methods}

A CT image is essentially a bitmap of each pixel's CT number; however, it also contains various artifacts due to the $\mathrm{X}$-ray photography and image reconstruction. Therefore, the effects of these artifacts, especially $\mathrm{BH}$, must be eliminated or reduced to ensure the accuracy of the CT numbers and therefore provide an accurate quantitative analysis.

$\mathrm{BH}$ artifacts cause the edges of a CT image to appear brighter than the center, such that the $\mathrm{CT}$ numbers along the edges of a sample are greater than those in the center. This occurs because the lower-energy X-rays are absorbed more readily than the higher energy ones when polychromatic X-rays pass through a sample near its center, where the transmission thickness is large.

Geet et al. (2000) estimated the density, $\rho$, and effective atomic number, $Z_{\mathrm{e}}$, via the dual-energy method using a micro X-ray CT scanner. The $\mu_{\mathrm{E}}$ coefficient, which is the effective LAC corresponding to the effective energy of the X-rays, is derived from Eq. (3) as:

$$
\mu_{\mathrm{E}} / \rho=A(E)+B(E) Z_{\mathrm{e}}^{3.8},
$$

where $A$ and $B$ are constants depending on $E$. The relationships among $\rho, Z_{\mathrm{e}}$, and $\mu$ are expressed as follows, using the $A$ and $B$ values calculated by approximating the relationship between $\mu_{\mathrm{E}} / \rho$ and $Z_{\mathrm{e}}^{3.8}$ values at two different tube voltages:

$$
\rho=\left(\mathrm{B}_{\mathrm{h}} \mu_{E l}-\mathrm{B}_{\mathrm{l}} \mu_{E \mathrm{l}}\right) /\left(\mathrm{B}_{\mathrm{h}} \mathrm{A}_{\mathrm{l}}-\mathrm{B}_{\mathrm{l}} \mathrm{A}_{\mathrm{h}}\right)
$$

and

$$
Z_{\mathrm{e}}=\left[\left(\mathrm{A}_{\mathrm{l}} \mu_{E \mathrm{~h}}-\mathrm{A}_{\mathrm{h}} \mu_{E 1}\right) /\left(\mathrm{B}_{\mathrm{h}} \mu_{E 1}-\mathrm{B}_{\mathrm{l}} \mu_{E \mathrm{~h}}\right)\right]^{\wedge}(1 / 3.8),
$$

where the $h$ and $l$ subscripts refer to the values derived from the high- and low-energy scans, respectively.

Iwamori et al. (2020) used the dual-energy method (tube voltages: 140 and $100 \mathrm{kV}$ ) to analyze the medical CT images of six different minerals with known densities and effective atomic numbers (quartz, calcite, fluorite, rhodochrosite, cryptomelane, and hematite). They found 
Table 4 Relationship among $N_{\text {CTM }}$ (calculated from the CT images at $140 \mathrm{kV}$ ), $\rho_{\mathrm{t}}$, and $Z_{\mathrm{et}}$ for each of the samples

\begin{tabular}{|c|c|c|c|c|c|c|c|c|c|c|c|c|c|c|c|c|}
\hline \multirow{2}{*}{$\begin{array}{l}\text { Fault } \\
\text { name }\end{array}$} & \multirow[t]{2}{*}{ Location } & \multirow[t]{2}{*}{ Material } & \multirow{2}{*}{$\begin{array}{l}\text { Sample } \\
\text { number }\end{array}$} & \multirow{2}{*}{$\begin{array}{l}\text { Pixel } \\
\text { count }\end{array}$} & \multirow[t]{2}{*}{$N_{\text {СтM }}$} & \multirow{2}{*}{$\begin{array}{l}\text { SD } \\
\text { of } \\
N_{\text {СTM }}\end{array}$} & \multirow[t]{2}{*}{$\rho_{\mathrm{t}}$} & \multicolumn{2}{|c|}{$\rho_{\mathrm{c}}=\mathrm{AN}_{\mathrm{CTM}}+\mathrm{B}$} & \multirow[t]{2}{*}{$\rho_{\mathrm{c}}$} & \multirow{2}{*}{$\begin{array}{l}\left(\rho_{\mathrm{c}}-\right. \\
\left.\rho_{\mathrm{t}}\right) / \rho_{\mathrm{t}}\end{array}$} & \multirow[t]{2}{*}{$Z_{\text {et }}$} & \multicolumn{2}{|c|}{$Z_{\text {ec }}=\mathrm{CN}_{\mathrm{CTM}}+\mathrm{D}$} & \multirow[t]{2}{*}{$Z_{\text {ec }}$} & \multirow{2}{*}{$\begin{array}{l}\left(Z_{\text {ec }}\right. \\
\left.-Z_{\text {et }}\right) \\
Z_{\text {et }}\end{array}$} \\
\hline & & & & & & & & $A$ & B & & & & $C$ & D & & \\
\hline \multirow[t]{16}{*}{$\overline{M T L}$} & \multirow[t]{5}{*}{$\mathrm{Hiji}$} & Cataclasite & HJ8-1 & 113570 & 1333 & 277 & 2.03 & \multirow[t]{6}{*}{$9.54 \times 10^{-4}$} & \multirow[t]{6}{*}{0.76} & 2.03 & $0.0 \%$ & 12.30 & \multirow[t]{6}{*}{$2.67 \times 10^{-4}$} & \multirow[t]{6}{*}{11.8} & 12.16 & $-1.1 \%$ \\
\hline & & Fault gouge & HJ8-2 & 122389 & 1109 & 192 & 1.70 & & & 1.82 & $7.1 \%$ & 12.04 & & & 12.10 & $0.5 \%$ \\
\hline & & Fault gouge & HJ8-3 & 73380 & 994 & 176 & 1.89 & & & 1.71 & $-9.5 \%$ & 12.24 & & & 12.07 & $-1.4 \%$ \\
\hline & & Fault gouge & HJ8-4 & 61075 & 1065 & 170 & 1.80 & & & 1.78 & $-1.1 \%$ & 12.12 & & & 12.08 & $-0.3 \%$ \\
\hline & & Cataclasite & HJ8-5 & 39613 & 1281 & 312 & 1.87 & & & 1.98 & $5.9 \%$ & 12.11 & & & 12.14 & $0.2 \%$ \\
\hline & Mizoguchi & Protolith & $M Z-5$ & 132804 & 2056 & 112 & 2.77 & & & 2.72 & $-1.8 \%$ & 12.38 & & & 12.35 & $-0.2 \%$ \\
\hline & \multirow[t]{10}{*}{ Awano-Tabiki } & Protolith & ATS-2 & 119482 & 1961 & 129 & 2.66 & \multirow[t]{4}{*}{$1.08 \times 10^{-3}$} & \multirow[t]{4}{*}{0.56} & 2.68 & $0.8 \%$ & 12.64 & \multirow[t]{4}{*}{$1.57 \times 10^{-3}$} & \multirow[t]{4}{*}{9.47} & 12.55 & $-0.7 \%$ \\
\hline & & & ATS-1 & 63283 & 1640 & 177 & 2.61 & & & 2.33 & $-10.7 \%$ & 12.63 & & & 12.04 & $-4.7 \%$ \\
\hline & & Cataclasite & AT-1 & 202405 & 1765 & 171 & 2.26 & & & 2.47 & $9.3 \%$ & 11.34 & & & 12.24 & $7.9 \%$ \\
\hline & & Fault gouge & AT-2 & 17591 & 1209 & 143 & 1.79 & & & 1.87 & $4.5 \%$ & 11.52 & & & 11.37 & $-1.3 \%$ \\
\hline & & Fault gouge & AT-3 & 11968 & 1665 & 104 & 2.31 & $1.19 \times 10^{-3}$ & 0.40 & 2.38 & $3.0 \%$ & 11.36 & $3.31 \times 10^{-3}$ & 5.87 & 11.38 & $0.2 \%$ \\
\hline & & Cataclasite & AT-4 & 103475 & 1864 & 161 & 2.61 & & & 2.62 & $0.4 \%$ & 11.45 & & & 12.04 & $5.2 \%$ \\
\hline & & Cataclasite & AT-5 & 52123 & 1718 & 123 & 2.44 & & & 2.44 & $0.0 \%$ & 11.42 & & & 11.56 & $1.2 \%$ \\
\hline & & Cataclasite & ATR-2,3 & 80661 & 1943 & 90 & 2.56 & & & 2.71 & $5.9 \%$ & 12.17 & & & 12.30 & $1.1 \%$ \\
\hline & & Mylonite & ATR-4 & 132075 & 1820 & 210 & 2.65 & & & 2.57 & $-3.0 \%$ & 12.13 & & & 11.89 & $-2.0 \%$ \\
\hline & & Protolith & $\mathrm{HA}-1$ & 134722 & 1908 & 209 & 2.76 & & & 2.67 & $-3.3 \%$ & 12.72 & & & 12.19 & $-4.2 \%$ \\
\hline Tsuruga & Oritodani & Protolith & $\mathrm{K}-1$ & 311751 & 1656 & 186 & 2.58 & $1.23 \times 10^{-3}$ & 0.45 & 2.49 & $-3.5 \%$ & 12.16 & $2.83 \times 10^{-4}$ & 11.6 & 12.07 & $-0.7 \%$ \\
\hline & & Cataclasite & $C-3$ & 234228 & 1699 & 164 & 2.47 & & & 2.54 & $2.8 \%$ & 12.11 & & & 12.08 & $-0.2 \%$ \\
\hline & & Cataclasite & $C-2$ & 241788 & 1471 & 93 & 2.16 & & & 2.26 & $4.6 \%$ & 12.10 & & & 12.02 & $-0.7 \%$ \\
\hline & & Fault gouge & T-3-1 & 94154 & 1492 & 70 & 2.28 & & & 2.29 & $0.4 \%$ & 11.96 & & & 12.02 & $0.5 \%$ \\
\hline & & Fault gouge & T-3-2 & 64118 & 1428 & 121 & 2.27 & & & 2.21 & $-2.6 \%$ & 12.08 & & & 12.00 & $-0.7 \%$ \\
\hline & & Fault gouge & $\mathrm{T}-3-3$ & 19558 & 1185 & 140 & 2.15 & $5.47 \times 10^{-4}$ & 1.42 & 2.07 & $-3.7 \%$ & 12.54 & $7.66 \times 10^{-4}$ & 12.1 & 13.01 & $3.7 \%$ \\
\hline & & Cataclasite & T-3-4 & 78628 & 1622 & 206 & 2.23 & & & 2.31 & $3.6 \%$ & 13.55 & & & 13.34 & $-1.5 \%$ \\
\hline & & Cataclasite & $C-1$ & 203854 & 1981 & 177 & 2.43 & & & 2.50 & $2.9 \%$ & 14.10 & & & 13.62 & $-3.4 \%$ \\
\hline & & Protolith & T-5 & 201781 & 2590 & 204 & 2.90 & & & 2.84 & $-2.1 \%$ & 13.96 & & & 14.08 & $0.9 \%$ \\
\hline Yamada & Mushu & Fault gouge & YDA-3 & 49921 & 1108 & 130 & 2.05 & $9.79 \times 10^{-4}$ & 0.85 & 1.93 & $-5.9 \%$ & 11.99 & $6.95 \times 10^{-4}$ & 11.2 & 11.97 & $-0.2 \%$ \\
\hline & & Cataclasite & YDA-4 & 165093 & 1333 & 119 & 1.98 & & & 2.16 & $9.1 \%$ & 12.05 & & & 12.13 & $0.7 \%$ \\
\hline & Karakawa & Protolith & YK-1 & 329517 & 1730 & 244 & 2.61 & & & 2.54 & $-2.7 \%$ & 12.45 & & & 12.40 & $-0.4 \%$ \\
\hline
\end{tabular}

that the modal CT number, $N_{\text {CTM }}$, which is calculated from the two-dimensional (2D) CT image whose peripheral CT values are excluded due to significant $\mathrm{BH}$, could be used to estimate the $\rho$ and $Z_{\mathrm{e}}$ values of the mineral samples. Iwamori et al. (2020) also reported that the recorded CT values for a single tube voltage $(140 \mathrm{kV})$ can be used to estimate $\rho$ and $Z_{\mathrm{e}}$ for the mineral samples since these parameters possess a positive correlation.

We have already highlighted the positive correlation between $\rho$ and $Z_{\mathrm{e}}$ for each analyzed fault and rock type in this study (Fig. 5c). Therefore, we investigated the relationship among $N_{\mathrm{CT}}, \rho$, and $Z_{\mathrm{e}}$ using the recorded CT images taken for a single tube voltage $(140 \mathrm{kV})$.

We used a third-generation medical X-ray scanner (Aquilion Precision TSX-304A 160-row multi-slice CT;
Canon Medical Systems Co., Ltd.; Otawara, Tochigi, Japan) at CRIEPI. The scanner has a $0.25 \mathrm{~mm}$ slice thickness and $0.098-0.313 \mathrm{~mm}$ pixel size. The X-ray tube has a W target and a $0.4 \mathrm{~mm} \times 0.5 \mathrm{~mm}$ focal size. Three-dimensional CT images were acquired using a single tube voltage $(140 \mathrm{kV})$ and a $300 \mathrm{mAs}$ tube current-time product. AIDR 3D (Canon Medical Systems) was used for iterative approximation reconstruction (hybrid iterative reconstruction method), with the FC30 reconstruction function employed. A CT image $(1,024 \times 1,024$ pixels $)$ of an arbitrary 2D cross section near the center of the sample was extracted from the $3 \mathrm{D}$ CT image. The effective energy of $140 \mathrm{kV}$ was set to $64.1 \mathrm{keV}$ based on Hubbell's (1982) measurement results for fixed irradiation using an aluminum plate. 


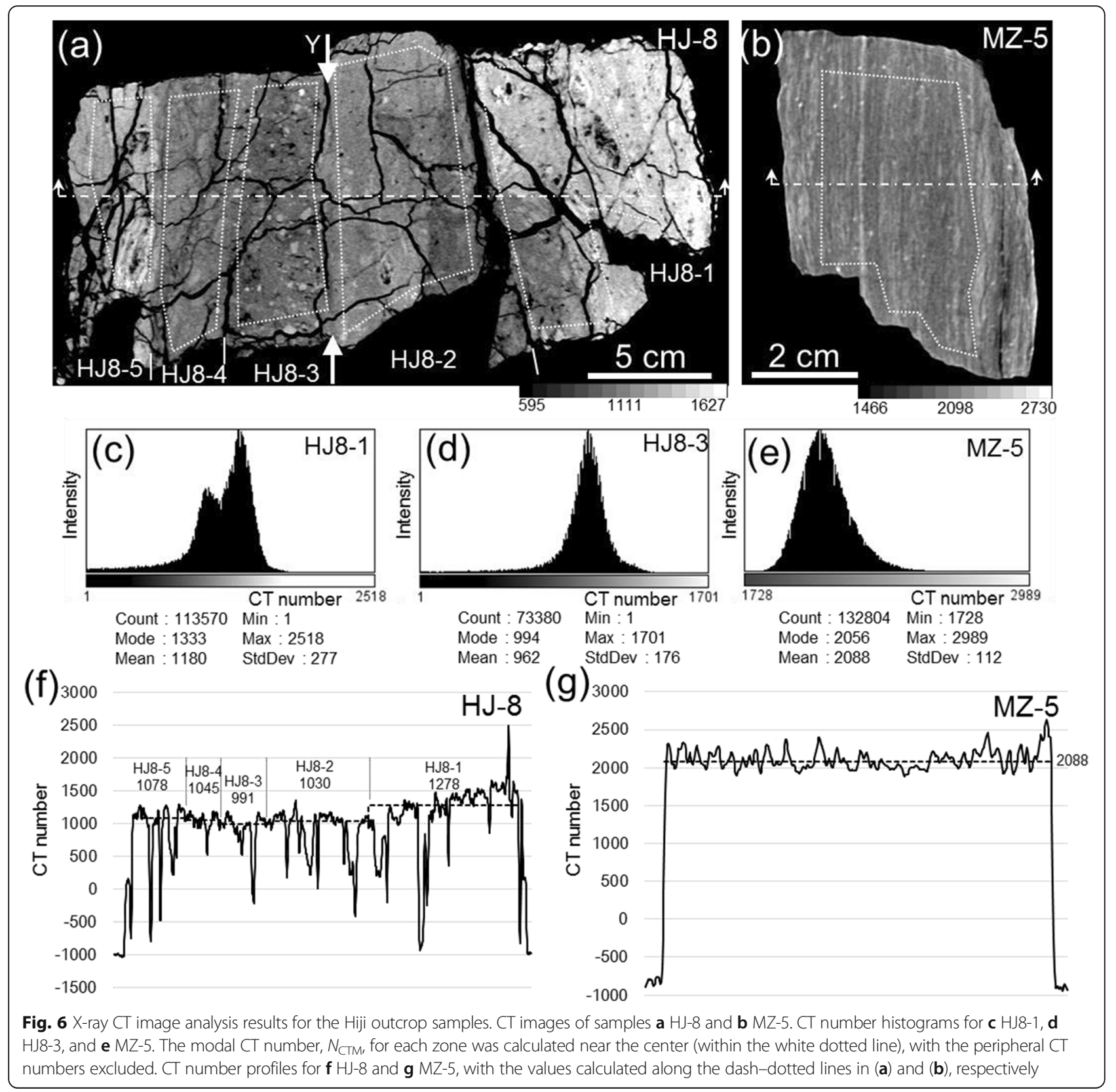

\subsection{Results}

Table 4 shows the X-ray CT image, density, and XRF analysis results. $N_{\text {СTM }}$ was obtained from the central part of each 2D CT image (within the white dotted perimeters in Figs. 6, 7, 8 and 9). The periphery of each CT image, where $\mathrm{BH}$ is significant and determined relative to the median CT value, $N_{\text {CTMedian }}$, calculated for the entire arbitrary crosssectional line (along the white dash-dotted line) using the method outlined in Iwamori et al. (2020), was excluded.

\subsubsection{The MTL at the Hiji outcrop}

The CT images for sample HJ-8, which is from the fault fracture zone in the Sanbagawa Belt, is dark at the fault gouge zones (HJ8-2, HJ8-3, and HJ8-4; Fig. 6a). The

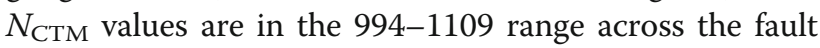
gouge, with the smallest value obtained within zone HJ8-3, which is in contact with the latest main fault plane $Y$. The cataclasite zones (HJ8-1 and HJ8-5), which are outside the fault gouge zones, appear brighter than the fault gouge, with $N_{\text {CTM }}$ values in the 1281-1333 range.

The CT images for sample MZ-5, a pelitic schist protolith in the Sanbagawa Belt, exhibit a striped pattern corresponding to planar schistosity (Fig. 6b) and possesses a $N_{\text {СTM }}$ value of 2056 . A narrow band $(\leq 1 \mathrm{~mm}$ wide) that is brighter than the rest of the image is 


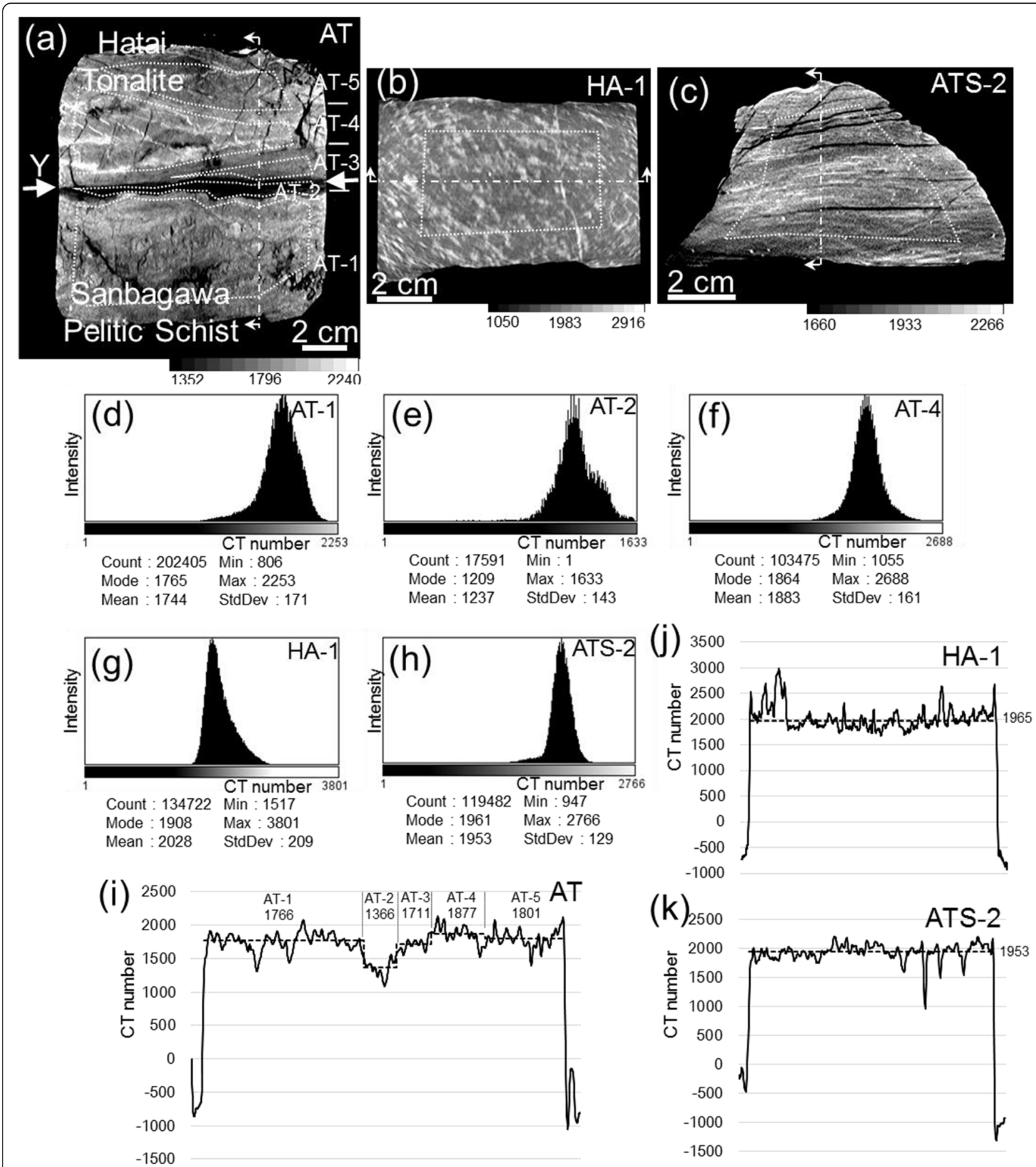

Fig. 7 X-ray CT image analysis results for the Awano-Tabiki outcrop samples. CT images of the a AT, $\mathbf{b}$ HA-1, and $\mathbf{c}$ ATS-2 samples. CT number histograms for the $\mathbf{d}$ AT-1, e AT-2, f AT-4, $\mathbf{g}$ HA-1, and $\mathbf{h}$ ATS-2 samples. The $N_{\text {CTM }}$ value for each zone was calculated near the center (within the white dotted lines in (a)-(c)), with the peripheral areas excluded. CT number profiles for $\mathbf{i}$ AT, $\mathbf{j} H A-1$, and $\mathbf{k}$ ATS-2, with the values calculated along the dash-dotted lines in (a)-(c), respectively

inferred to be a phengite vein, which has a greater effective atomic number than either quartz or albite.

Example histograms of the CT values in each of the sampled zones are shown in Fig. 6c-e. Approximately
40,000-130,000 pixels are analyzed in each region, with the $N_{\text {СTM }}$ values generally following a normal distribution and possessing a standard deviation of 112-312 (Table 4). There may either be an increase in the 

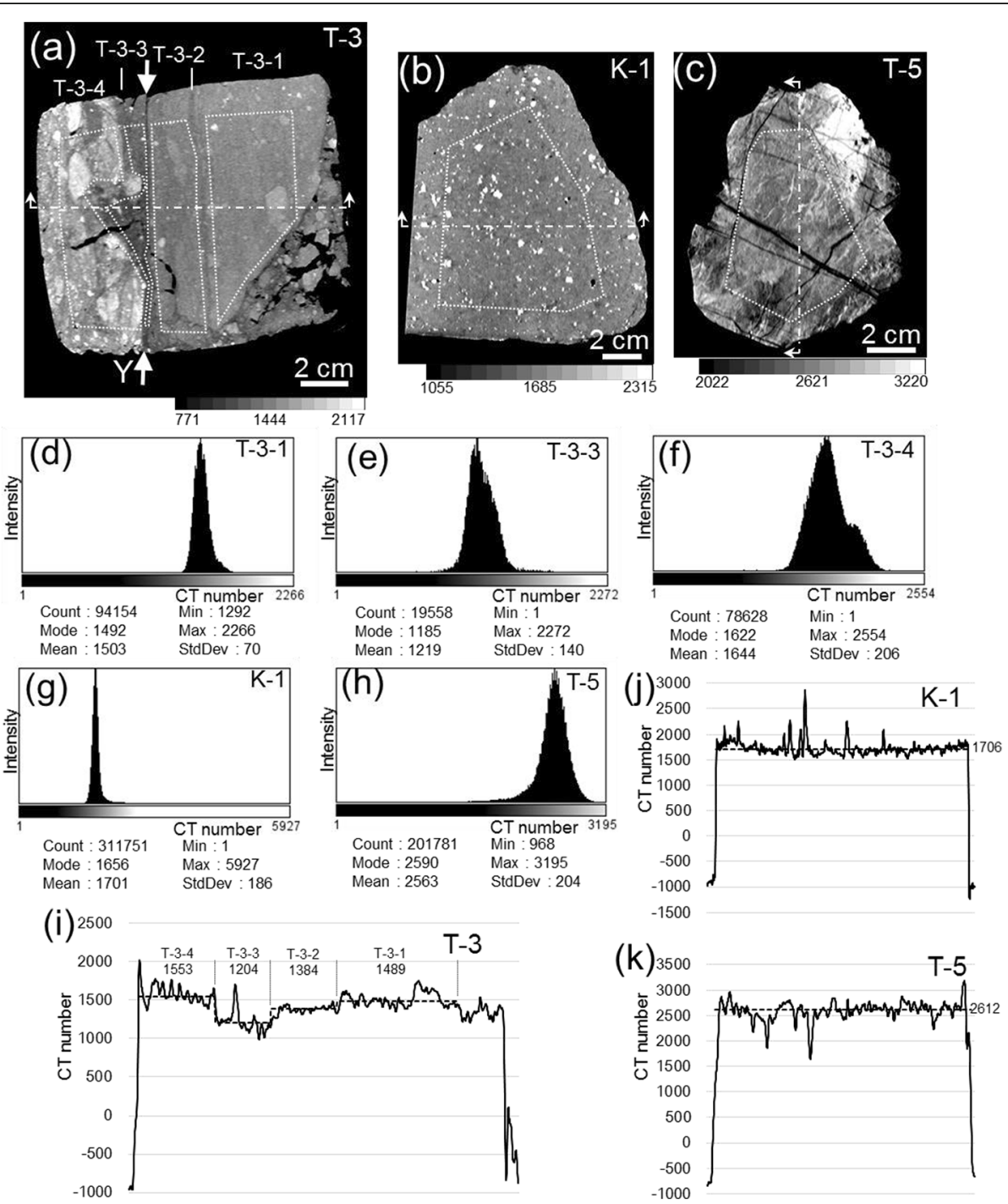

Fig. 8 X-ray CT image analysis results for the Oritodani outcrop samples. CT images of samples $\mathbf{a} T-3, \mathbf{b}$ K-1, and $\mathbf{c}$ T-5. CT number histograms for d T-3-1, e T-3-3, f T-3-4, $\mathbf{g}$ K-1, and $\mathbf{h}$ T-5. The $N_{\text {CTM }}$ value in each zone was calculated near the center (within the white dotted lines in (a)-(c)), with the peripheral values excluded. CT number profiles for $\mathbf{i} T-3, \mathbf{j}$ K-1, and $\mathbf{k} T-5$, with the values calculated along the dash-dotted lines in (a)-(c), respectively

frequency to values lower than $N_{\text {CTM }}$, or a small side peak that is lower than $N_{\text {СтM }}$ if the sample contains many cracks; however, $N_{\mathrm{CTM}}$ corresponds to the CT value of the matrix, with the influence of cracks excluded.

Figure $6 \mathrm{f}$ and $\mathrm{g}$ show the $\mathrm{CT}$ value distributions along the white dash-dotted lines in the CT image. We note that the $N_{\text {CTMedian }}$ values (HJ-8: 991-1278, MZ-5: 2088) are almost consistent with the $N_{\text {СТM }}$ values that were calculated from the 2D CT images.

The $N_{\text {СТM }}-\rho_{\mathrm{t}}$ relationship for Sanbagawa pelitic schist possesses a high positive correlation $\left(\rho_{\mathrm{t}}=9.54 \times 10^{-4}\right.$ $N_{\text {CTM }}+0.76, \gamma=0.958$; Fig. 10a). The calculated density from this equation, $\rho_{\mathrm{c}}$, is consistent with the real value, $\rho_{\mathrm{t}}$, and possesses an error of $<9.5 \%$ (Table 4 ).
The $N_{\text {СTM }}-Z_{\text {et }}$ relationship $\left(Z_{\text {et }}=2.67 \times 10^{-4} N_{\text {CTM }}+\right.$ 11.8) can be derived from the abovementioned $N_{\text {СтM }}-\rho_{\mathrm{t}}$ relationship; the $\rho_{\mathrm{t}}-Z_{\mathrm{et}}$ relationship is shown in Fig. $5 \mathrm{c}$ $\left(Z_{\mathrm{et}}=0.28 \rho_{\mathrm{t}}+11.6, \gamma=0.847\right)$. The effective atomic number calculated from this equation, $Z_{\mathrm{ec}}$, is consistent with the real value, $Z_{\mathrm{et}}$, and possesses an error of $<1.4 \%$ (Table 4).

\subsubsection{The MTL at the Awano-Tabiki outcrop}

The imaging results for samples AT, HA-1, and ATS-2 (Fig. $7 \mathrm{a}-\mathrm{C}$ ) are representative of the seven samples (AT, ATR-2, ATR-3, ATR-4, ATS-1, ATS-2, and HA-1) collected from the Awano-Tabiki outcrop.

The CT image for sample AT, which was taken from rocks in the fault fracture zone that formed during the 


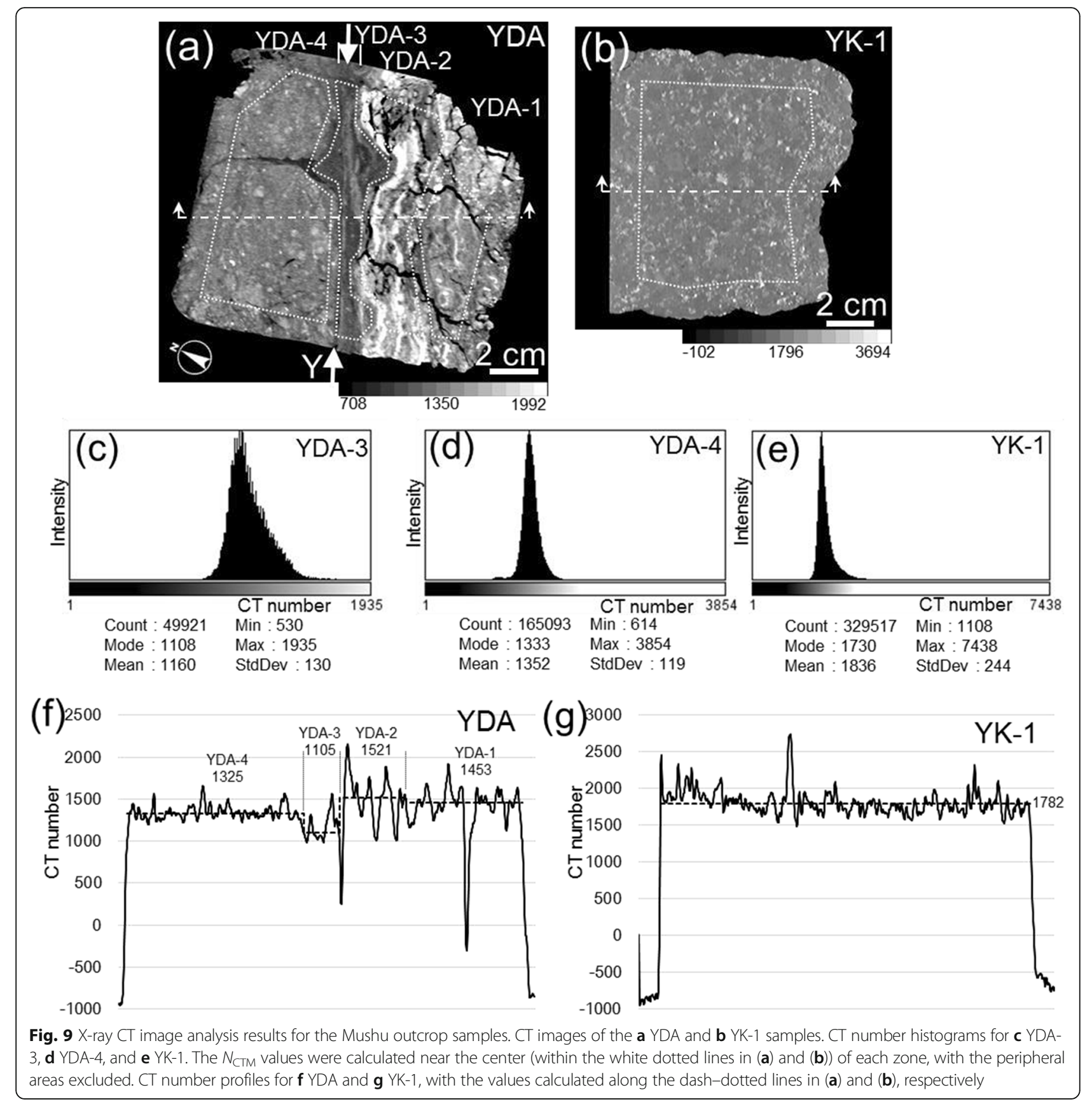

most recent fault activity, appears dark in the fault gouge (AT-2 and AT-3) surrounding the main fault plane $Y$

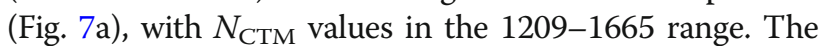
smallest $N_{\text {СTM }}$ value was observed in AT-2, which is in contact with the latest main fault plane $Y$. The cataclasite samples (AT-1, AT-4, and AT-5), which are outside of the fault gouge zone, produce brighter images than the fault gouge ones, with $N_{\text {СТM }}$ values in the 1718-1864 range.

Sample HA-1, a Hatai tonalite protolith from the Ryoke Belt, possesses both dark-gray and mottled white regions throughout the $\mathrm{CT}$ images (Fig. 7b), with a $N_{\text {СтM }}$ value of 1908 . A 1-2 mm thick band that appears brighter than the rest of the image is inferred to be hornblende and chlorite, both of which have larger effective atomic numbers than quartz and plagioclase.

Sample ATS-2, a pelitic schist protolith from the Sanbagawa Belt, possesses striped patterns corresponding to planar schistosity in the CT images (Fig. 7c), with a $N_{\text {СTM }}$ value of 1961. A narrow band (at most $\sim 1 \mathrm{~mm}$ wide) that appears brighter than the rest of the image 

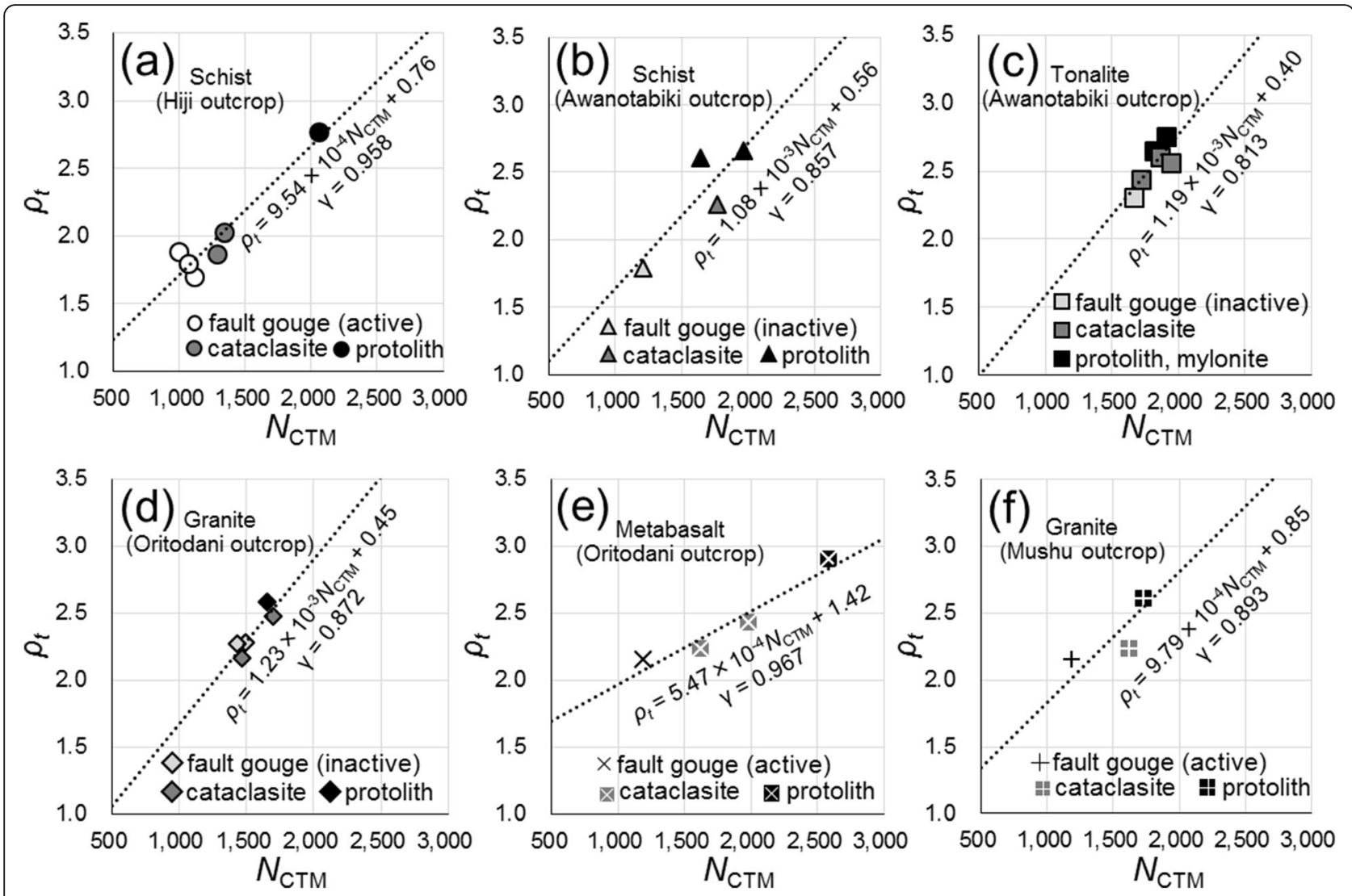

Fig. $10 \rho_{\mathrm{t}}-N_{\text {CTM }}$ crossplots for the sampled fault rocks and protoliths. a Schist (Hiji outcrop). b Schist (Awano-Tabiki outcrop). c Tonalite (Awano-Tabiki outcrop). d Granite (Oritodani outcrop). e Metabasalt (Oritodani outcrop). f Granite (Mushu outcrop)

is inferred to be a thin layer containing phengite and calcite, both of which have larger effective atomic numbers than quartz.

Example CT value histograms for each zone are shown in Fig. 7d-h. Approximately 12,000-200,000 pixels are analyzed in each zone, with the $N_{\text {СTM }}$ values generally following a normal distribution and possessing a standard deviation of 90-210 (Table 4). There may be a slight increase in the frequency to values higher than $N_{\text {CTM }}$ due to the influence of minerals with a large effective atomic number in some instances; however, $N_{\text {СтM }}$ corresponds to the $\mathrm{CT}$ value of the matrix, with the influence of these minerals excluded.

Figure $7 \mathrm{i}-\mathrm{k}$ show the $\mathrm{CT}$ value distributions along the white dash-dotted line in the CT image. We note that the $N_{\text {CTMedian }}$ values (AT: 1386-1801, HA-1: 1965, ATS-2: 1953) are almost consistent with the $N_{\text {СTM }}$ values calculated from the $2 \mathrm{D} \mathrm{CT}$ images.

The $N_{\mathrm{CTM}}-\rho_{\mathrm{t}}$ relationships for the Sanbagawa pelitic schist and Ryoke tonalite possess high positive correlations (pelitic schist: $\rho_{\mathrm{t}}=1.08 \times 10^{-3} N_{\mathrm{CTM}}+0.56, \gamma=$ 0.857; tonalite: $\rho_{\mathrm{t}}=1.19 \times 10^{-3} N_{\mathrm{CTM}}+0.40, \gamma=0.813$; Fig. $10 \mathrm{~b}, \mathrm{c})$. The $\rho_{\mathrm{c}}$ values are consistent with the $\rho_{\mathrm{t}}$ values and possess errors of $<10.7 \%$ (Table 4 ).
The $N_{\text {СтM }}-Z_{\text {et }}$ relationships (pelitic schist: $Z_{\text {et }}=1.57$ $\times 10^{-3} N_{\text {СтM }}+9.47$; tonalite: $Z_{\text {et }}=3.31 \times 10^{-3} N_{\text {СТM }}+$ 5.87) can be derived from the abovementioned $N_{\mathrm{CTM}}-\rho_{\mathrm{t}}$ relationships; the $\rho_{\mathrm{t}}-Z_{\mathrm{et}}$ relationships are shown in Fig. $5 \mathrm{c}$ (pelitic schist: $Z_{\mathrm{et}}=1.45 \rho_{\mathrm{t}}+8.7, \gamma=0.827$; tonalite: $\left.Z_{\text {et }}=2.78 \rho_{\mathrm{t}}+4.76, \gamma=0.802\right)$. The $Z_{\mathrm{ec}}$ values are consistent with the $Z_{\text {et }}$ values and possess errors of < 7.9\% (Table 4).

\subsubsection{The Tsuruga Fault at the Oritodani outcrop}

The CT results for samples T-3, K1, and T-5 (Fig. 8a-c) are representative of the five samples (T-3, C-2, K-1, C1 , and T-5) collected from the Oritodani outcrop.

Sample T-3, which was taken from the rocks in the fault fracture zone that formed during the most recent fault activity, appears dark in the fault gouge (T-3-1, T$3-2$, and T-3-3) around the main fault plane $Y$ in the CT image (Fig. 8a), with $N_{\text {CTM }}$ values in the 1185-1492

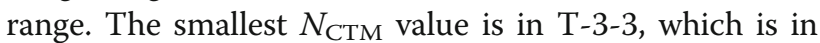
contact with the latest main fault plane $Y$. We consider T-3-2 to be possibly affected by the most recent fault activity based on our abovementioned analysis, but its $N_{\text {СтM }}$ value is 1428 , which is about the same as that in T-3-1 and exceeds that in AT-2, a fault gouge along an 


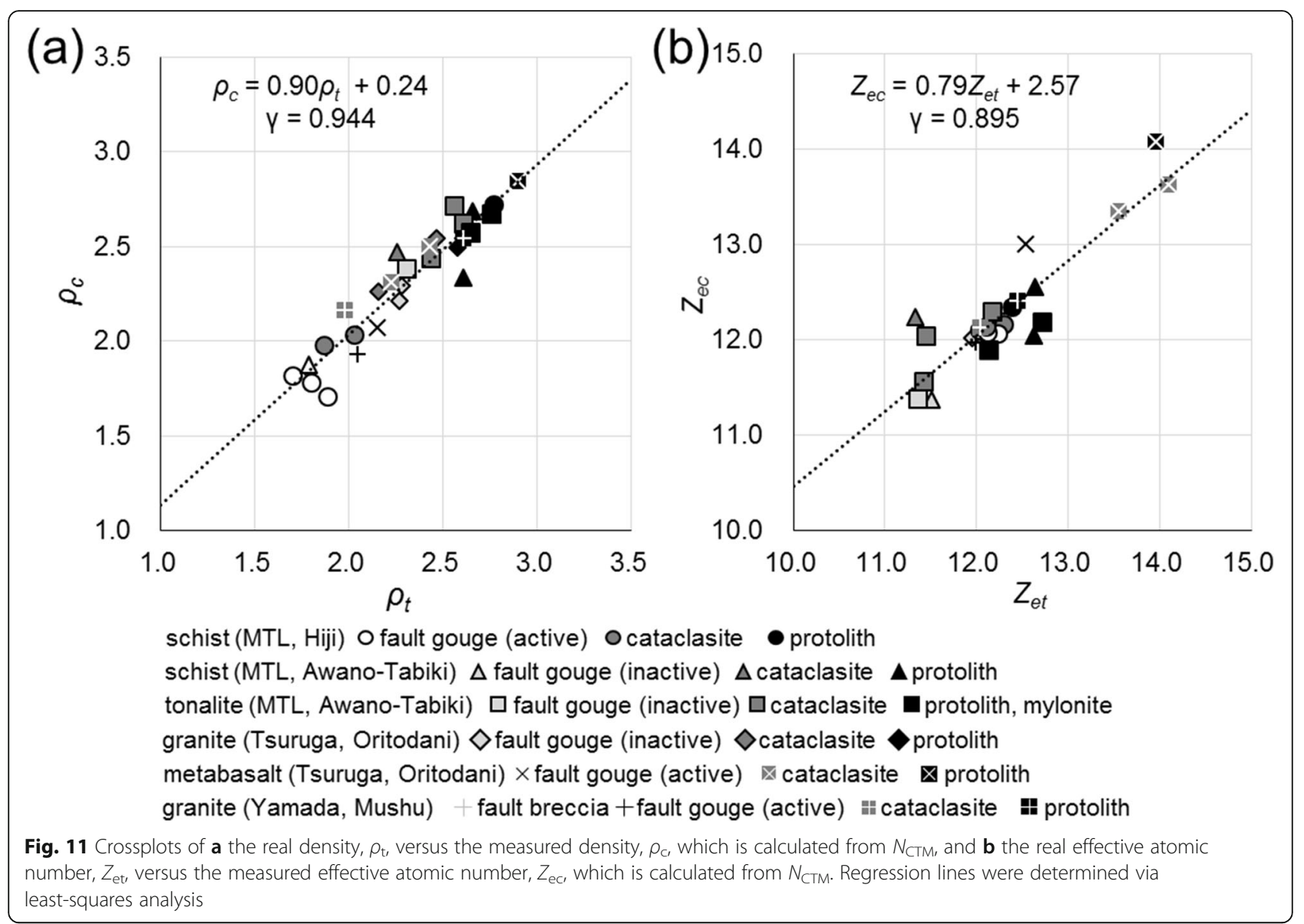

inactive fault. Furthermore, the observed microstructures in T-3 suggest that repetitive fault activity, which is indicative of an active fault, is limited to fault gouge T-3-3. Therefore, we classify T-3-1 and T-3-2 as inactive fault gouge, and T-3-3 as active fault gouge in this analysis. The cataclasite (T-3-4) outside of the fault gouge appears brighter than the fault gouge, with a $N_{\text {СтM }}$ value of 1622.

Sample K-1, a Koujaku granite protolith, possesses dark-gray and fine-grained white areas throughout the CT images (Fig. 8b), with a $N_{\text {СTM }}$ value of 1656 . The small white areas ( $\leq 2 \mathrm{~mm}$ diameter) in the image are inferred to be biotite, which has a larger effective atomic number than either quartz or plagioclase.

Sample T-5, which is a metabasalt protolith, is largely gray in the CT image, with the exception of a white area at the upper right of the sample (Fig. 8c) and has a

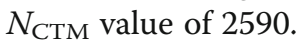

Example CT value histograms for each zone are shown in Fig. 8d-h. Approximately 20,000-310,000 pixels are analyzed in each region, with the $N_{\text {СтM values generally }}$ following a normal distribution and possessing a standard deviation of 70-206 (Table 4). There may be a slight increase in the frequency to values above $N_{\text {CTM }}$ due to the influence of minerals with a large effective atomic number in some instances, but $N_{\text {СTM }}$ corresponds to the CT value of the matrix, with the influence of these minerals excluded.

Figure $8 \mathrm{i}-\mathrm{k}$ show the $\mathrm{CT}$ value distributions along the white dash-dotted lines in the CT images We note that the $N_{\text {CTMedian }}$ values (T-3: 1204-1553, K-1: 1706, ATS2: 2612) are almost consistent with the $N_{\text {СTM }}$ values calculated from the 2D CT images.

The $N_{\mathrm{CTM}}-\rho_{\mathrm{t}}$ relationships for Koujaku granite and metabasalt have high positive correlations (granite: $\rho_{\mathrm{t}}=$ $1.23 \times 10^{-3} N_{\text {СTM }}+0.45, \gamma=0.872$; metabasalt: $\rho_{\mathrm{t}}=5.47$ $\times 10^{-4} N_{\text {CTM }}+1.42, \gamma=0.967$; Fig. $10 \mathrm{~d}$, e). The $\rho_{\mathrm{c}}$ values are the $\rho_{\mathrm{t}}$ values and possess errors of $<3.7 \%$ (Table 4 ).

The $N_{\text {СтM }}-Z_{\text {et }}$ relationships (granite: $Z_{\text {et }}=2.83 \times 10^{-4}$ $N_{\text {CTM }}+11.6$; metabasalt: $Z_{\text {et }}=7.66 \times 10^{-4} N_{\text {CTM }}+$ 12.1) can be derived from the abovementioned $N_{\mathrm{CTM}}-\rho_{\mathrm{t}}$ relationships; the $\rho_{\mathrm{t}}-Z_{\text {et }}$ relationships are shown in Fig. 5c (granite: $Z_{\mathrm{et}}=0.23 \rho_{\mathrm{t}}+11.5, \gamma=0.528$; metabasalt: $\left.Z_{\mathrm{et}}=1.40 \rho_{\mathrm{t}}+10.1, \gamma=0.669\right)$. The $Z_{\mathrm{ec}}$ values are consistent with the $Z_{\text {et }}$ values and possess errors of $<3.7 \%$ (Table 4 ). 
Table 5 Comparison of $\rho_{\mathrm{t}}, Z_{\mathrm{et}}, N_{\mathrm{CTM}}$, and the rock/protolith ratios $\left(\rho_{\mathrm{t}}\right.$ and $\left.Z_{\mathrm{et}}{ }^{3.8}\right)$ for each of the analyzed samples

\begin{tabular}{|c|c|c|c|c|c|c|c|c|c|c|c|}
\hline \multirow[t]{2}{*}{$\begin{array}{l}\text { Fault } \\
\text { name }\end{array}$} & \multirow[t]{2}{*}{ Location } & \multirow[t]{2}{*}{ Material } & \multirow[t]{2}{*}{$\begin{array}{l}\text { Sample } \\
\text { number }\end{array}$} & \multirow[t]{2}{*}{$\rho_{\mathrm{t}}$} & \multirow[t]{2}{*}{$Z_{\text {et }}$} & \multirow[t]{2}{*}{$N_{\text {СтM }}$} & \multicolumn{3}{|c|}{$\begin{array}{l}\text { Rock/Protolith ratio andcompared } \\
\text { protolith (No.) }\end{array}$} & \multirow[t]{2}{*}{ Remarks } & \\
\hline & & & & & & & $\rho_{\mathrm{t}}$ & $Z_{\mathrm{et}}^{3.8}$ & protolith (No.) & & \\
\hline \multirow[t]{16}{*}{ MTL } & \multirow[t]{5}{*}{ Hiji } & Cataclasite & HJ8-1 & 2.03 & 12.30 & 1333 & 0.73 & 0.98 & $(M Z-5)$ & \multirow[t]{6}{*}{ schist } & \multirow[t]{6}{*}{ Hiji } \\
\hline & & Fault gouge & HJ8-2 & 1.70 & 12.04 & 1109 & 0.61 & 0.90 & (MZ-5) & & \\
\hline & & Fault gouge & HJ8-3 & 1.89 & 12.24 & 994 & 0.68 & 0.96 & (MZ-5) & & \\
\hline & & Fault gouge & HJ8-4 & 1.80 & 12.12 & 1065 & 0.65 & 0.92 & (MZ-5) & & \\
\hline & & Cataclasite & HJ8-5 & 1.87 & 12.11 & 1281 & 0.68 & 0.92 & (MZ-5) & & \\
\hline & Mizoguchi & Protolith & $M Z-5$ & 2.77 & 12.38 & 2056 & 1.00 & 1.00 & (MZ-5) & & \\
\hline & \multirow[t]{10}{*}{ Awano-Tabiki } & \multirow[t]{2}{*}{ Protolith } & ATS-2 & 2.66 & 12.64 & 1961 & 1.00 & 1.00 & (ATS-2) & \multirow[t]{4}{*}{ schist } & \multirow[t]{4}{*}{ Awanotabiki } \\
\hline & & & ATS-1 & 2.61 & 12.63 & 1640 & 0.98 & 1.00 & (ATS-2) & & \\
\hline & & Cataclasite & AT-1 & 2.26 & 11.34 & 1765 & 0.85 & 0.66 & (ATS-2) & & \\
\hline & & Fault gouge & AT-2 & 1.79 & 11.52 & 1209 & 0.67 & 0.70 & (ATS-2) & & \\
\hline & & Fault gouge & AT-3 & 2.31 & 11.36 & 1665 & 0.84 & 0.65 & $(\mathrm{HA}-1)$ & \multirow[t]{6}{*}{ tonalite } & \multirow[t]{6}{*}{ Ryoke } \\
\hline & & Cataclasite & AT-4 & 2.61 & 11.45 & 1864 & 0.95 & 0.67 & $(\mathrm{HA}-1)$ & & \\
\hline & & Cataclasite & AT-5 & 2.44 & 11.42 & 1718 & 0.89 & 0.66 & $(\mathrm{HA}-1)$ & & \\
\hline & & Cataclasite & ATR-2 & 2.56 & 12.17 & 1943 & 0.93 & 0.85 & $(\mathrm{HA}-1)$ & & \\
\hline & & Mylonite & ATR-4 & 2.65 & 12.13 & 1820 & 0.96 & 0.83 & $(\mathrm{HA}-1)$ & & \\
\hline & & Protolith & $\mathrm{HA}-1$ & 2.76 & 12.72 & 1908 & 1.00 & 1.00 & $(\mathrm{HA}-1)$ & & \\
\hline \multirow[t]{9}{*}{ Tsuruga } & \multirow[t]{9}{*}{ Oritodani } & Protolith & $\mathrm{K}-1$ & 2.58 & 12.16 & 1656 & 1.00 & 1.00 & $(K-1)$ & \multirow[t]{5}{*}{ granite } & \multirow[t]{5}{*}{ Koujaku } \\
\hline & & Cataclasite & $C-3$ & 2.47 & 12.11 & 1699 & 0.96 & 0.98 & $(K-1)$ & & \\
\hline & & Cataclasite & $C-2$ & 2.16 & 12.10 & 1471 & 0.84 & 0.98 & $(K-1)$ & & \\
\hline & & Fault gouge & T-3-1 & 2.28 & 11.96 & 1492 & 0.88 & 0.94 & $(K-1)$ & & \\
\hline & & Fault gouge & T-3-2 & 2.27 & 12.08 & 1428 & 0.88 & 0.98 & $(K-1)$ & & \\
\hline & & Fault gouge & $\mathrm{T}-3-3$ & 2.15 & 12.54 & 1185 & 0.74 & 0.67 & $(T-5)$ & metabasalt & Metabasalt \\
\hline & & Cataclasite & $\mathrm{T}-3-4$ & 2.23 & 13.55 & 1622 & 0.77 & 0.89 & $(T-5)$ & & \\
\hline & & Cataclasite & $C-1$ & 2.43 & 14.10 & 1981 & 0.84 & 1.04 & (T-5) & & \\
\hline & & Protolith & T-5 & 2.90 & 13.96 & 2590 & 1.00 & 1.00 & (T-5) & & \\
\hline \multirow[t]{3}{*}{ Yamada } & \multirow[t]{2}{*}{ Mushu } & Fault gouge & YDA-3 & 2.05 & 11.99 & 1108 & 0.79 & 0.87 & $(\mathrm{YK}-1)$ & \multirow[t]{3}{*}{ granite } & Miyazu \\
\hline & & Cataclasite & YDA-4 & 1.98 & 12.05 & 1333 & 0.76 & 0.88 & $(\mathrm{YK}-1)$ & & \\
\hline & Karakawa & Protolith & YK-1 & 2.61 & 12.45 & 1730 & 1.00 & 1.00 & $(\mathrm{YK}-1)$ & & \\
\hline Mean of a & all samples & Fault gouge & - & 1.92 & 12.19 & 1092 & 0.69 & 0.86 & - & Avtive fault & \\
\hline & & Fault gouge & - & 2.16 & 11.73 & 1449 & 0.82 & 0.82 & - & Inactive fault & \\
\hline & & Cataclasite & - & 2.28 & 12.25 & 1637 & 0.84 & 0.86 & - & - & \\
\hline & & Protolith, Mylonite & - & 2.69 & 12.63 & 1920 & 1.00 & 1.00 & - & - & \\
\hline
\end{tabular}

\subsubsection{The Yamada Fault at the Mushu outcrop}

Sample YDA, which is from the Miyazu granite in the fault fracture zone at the Mushu outcrop, appears dark in the fault gouge of the CT image (YDA-3; Fig. 9a), with a $N_{\text {СTM }}$ value of 1108 . The smallest $N_{\text {CTM }}$ value is in YDA-3, which is adjacent to the latest main fault plane $Y$. The cataclasite zone (YDA-4), which is outside of the fault gouge, is brighter than the fault gouge, with a $N_{\text {Стм }}$ value of 1333.

Sample YK-1, a Miyazu granite protolith, possesses dark-gray and fine-grained white areas throughout the
CT images (Fig. 9b), with a $N_{\text {CTM }}$ value of 1730 . The white area ( $\leq 2 \mathrm{~mm}$ diameter) in the image is inferred to be biotite, which has a larger effective atomic number than both quartz and plagioclase.

Example CT value histograms for each zone are shown in Fig. 9c-e. Approximately 50,000-330,000 pixels were analyzed in each region, with the $N_{\text {СтM }}$ values generally following a normal distribution and possessing a standard deviation of 119-224 (Table 4). There may be a slight increase in the frequency to values above $N_{\text {СтM }}$ due to the influence of minerals with a large effective 
Table 6 Statistics of the determined $N_{\text {CTM }}$ values and rock/protolith ratios $\left(\rho_{\mathrm{t}}\right.$ and $Z_{\mathrm{et}}{ }^{3.8}$ )

\begin{tabular}{|c|c|c|c|c|c|c|c|c|c|c|}
\hline \multirow[t]{2}{*}{ Item } & \multicolumn{4}{|l|}{$N_{\text {СтM }}$} & \multicolumn{3}{|c|}{ Rock/Protolith $\rho_{\mathrm{t}}$ ratio } & \multicolumn{3}{|c|}{ Rock/Protolith $Z_{\mathrm{et}}^{3.8}$ ratio } \\
\hline & $\begin{array}{l}\text { Fault } \\
\text { gouge } \\
\text { (Active) }\end{array}$ & $\begin{array}{l}\text { Fault gouge } \\
\text { (Inactive) }\end{array}$ & Cataclasite & $\begin{array}{l}\text { Protolith, } \\
\text { Mylonite }\end{array}$ & $\begin{array}{l}\text { Fault } \\
\text { gouge } \\
\text { (Active) }\end{array}$ & $\begin{array}{l}\text { Fault gouge } \\
\text { (Inactive) }\end{array}$ & $\overline{\text { Cataclasite }}$ & $\begin{array}{l}\text { Fault } \\
\text { gouge } \\
\text { (Active) }\end{array}$ & $\begin{array}{l}\text { Fault gouge } \\
\text { (Inactive) }\end{array}$ & Cataclasite \\
\hline$\overline{\operatorname{Max}}$ & 1185 & 1665 & 1981 & 2590 & 0.79 & 0.88 & 0.96 & 0.96 & 0.98 & 1.04 \\
\hline $75 \%$ & 1109 & 1535 & 1815 & 1985 & 0.74 & 0.88 & 0.91 & 0.92 & 0.95 & 0.98 \\
\hline Median & 1108 & 1460 & 1699 & 1864 & 0.68 & 0.86 & 0.84 & 0.90 & 0.82 & 0.89 \\
\hline $25 \%$ & 1065 & 1373 & 1402 & 1712 & 0.65 & 0.80 & 0.77 & 0.87 & 0.69 & 0.76 \\
\hline Min & 994 & 1209 & 1281 & 1640 & 0.61 & 0.67 & 0.68 & 0.67 & 0.65 & 0.66 \\
\hline STD & 62 & 163 & 239 & 288 & 0.06 & 0.09 & 0.09 & 0.10 & 0.14 & 0.13 \\
\hline Mean & 1092 & 1449 & 1637 & 1920 & 0.69 & 0.82 & 0.84 & 0.86 & 0.82 & 0.86 \\
\hline $\begin{array}{l}\text { Number } \\
\text { of data }\end{array}$ & 5 & 4 & 11 & 8 & 5 & 4 & 11 & 5 & 4 & 11 \\
\hline
\end{tabular}

atomic number in some instances; however, $N_{\mathrm{CTM}}$ corresponds to the $\mathrm{CT}$ value of the matrix, with the influence of these minerals excluded.

Figure $9 \mathrm{f}$ and $\mathrm{g}$ show the CT value distributions along the white dash-dotted lines in the CT image. We note that the $N_{\text {CTMedian }}$ values (YDA: 1105-1325, YK-1: 1782) are almost consistent with the $N_{\text {CTM }}$ values that were calculated from the 2D CT images.

The $N_{\mathrm{CTM}}-\rho_{\mathrm{t}}$ relationship for Miyazu Granite has a high positive correlation $\left(\rho_{\mathrm{t}}=9.79 \times 10^{-4} N_{\mathrm{CTM}}+0.85\right.$, $\gamma=0.893$; Fig. 10f). The $\rho_{\mathrm{c}}$ value is consistent with $\rho_{\mathrm{t}}$ and possesses the error of $<9.1 \%$ (Table 4 ).

The $N_{\mathrm{CTM}}-Z_{\text {et }}$ relationship $\left(Z_{\text {et }}=6.95 \times 10^{-4} N_{\text {CTM }}+\right.$ $11.2)$ can be derived from the abovementioned $N_{\text {CTM }}-\rho_{\mathrm{t}}$ relationship; the $\rho_{\mathrm{t}}-Z_{\text {et }}$ relationship is shown in Fig. $5 \mathrm{c}$ $\left(Z_{\text {et }}=0.71 \rho_{\mathrm{t}}+10.6, \gamma=0.975\right)$. The $Z_{\text {ec }}$ value is consistent with $Z_{\text {et }}$, and possesses an error of $<0.7 \%$ (Table 4 ).

\section{Discussion}

We have concluded that $N_{\text {CTM }}$ can be used to estimate $\rho_{\mathrm{t}}$ and $Z_{\text {et }}$ for the protolith and fault rock samples. Here we further investigate the $\rho_{\mathrm{t}}-\rho_{\mathrm{c}}$ and $Z_{\mathrm{et}}-Z_{\mathrm{ec}}$ relationships, the lowest density domain, and the youngest active domain relationships in major fault zones, as well as the fault rock characteristics based on the $N_{\mathrm{CTM}}-$ rock/ protolith ratio $\left(\rho_{\mathrm{t}}\right.$ and $\left.Z_{\mathrm{et}}\right)$ relationship, to validate the feasibility of employing CT-based methods to characterize fault zones.

\section{$5.1 \rho_{\mathrm{t}}-\rho_{\mathrm{c}}$ and $Z_{\mathrm{et}}-Z_{\mathrm{ec}}$ relationships}

There is no significant difference in the $\rho-\phi$ relationship for various fault rock and protolith types (Fig. 5b), whereas the trend of the $\rho_{\mathrm{t}}-Z_{\text {et }}$ relationship appears to be dependent on the analyzed fault rock/protolith type (Fig. 5c). This indicates that $N_{\mathrm{CTM}}$, which is a function of $\rho$ and $Z_{\mathrm{e}}$, must be treated as an effective parameter for examining fault rock and protolith characteristics by fault rock/protolith type. We observe strong correlations between $\rho_{\mathrm{c}}$ and $\rho_{\mathrm{t}}$, and $Z_{\mathrm{ec}}$ and $Z_{\mathrm{et}}$ for each fault rock and protolith type, as shown in Fig. $11\left(\rho: \gamma=0.944, Z_{\mathrm{e}}\right.$ : $\gamma=0.895)$. Therefore, $N_{\text {CTM }}$, which is calculated by fault rock/protolith type, should be a reliable parameter for calculating the $\rho_{\mathrm{t}}$ and $Z_{\text {et }}$ values of a given rock sample and determining its fault rock/protolith characteristics.

\subsection{Fault rock characteristics based on the $N_{\text {СтM }}$-rock/ protolith ratio $\left(\rho_{\mathrm{t}}\right.$ and $\left.Z_{\text {et }}\right)$ relationship}

We have demonstrated that $\rho_{\mathrm{t}}, Z_{\text {et }}$, and $N_{\mathrm{CTM}}$ all decrease as the main fault plane, identified by outcrop observation, is approached Furthermore, $\rho_{\mathrm{t}}$ is affected by $Z_{\text {et }}$, as shown in Fig. $5 \mathrm{c}$, with a distinct $\rho_{\mathrm{t}}-Z_{\mathrm{et}}$ relationship for each fault and protolith type. Therefore, the effect of $Z_{\text {et }}$ on $\rho_{\mathrm{t}}$ is suppressed by using the rock/protolith density ratio of each fault and protolith type.

Table 5 shows the results of the analyzed fault rock characteristics based on the relationships between $N_{\mathrm{CTM}}$ and the $\rho_{\mathrm{t}}$ and $Z_{\mathrm{et}}$ rock/protolith ratios. The statistics of

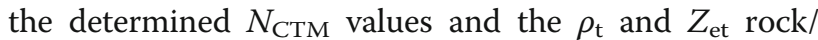
protolith ratios are provided in Table 6 and Fig. 12a-c.

The $N_{\text {CTM }}$ values (taken at $140 \mathrm{kV}$ ) were $\sim 1900 \pm 300$ for the protoliths, $\sim 1650 \pm 250$ for cataclasite, $\sim 1450 \pm$ 200 for the fault gouge along inactive faults, and $\sim 1100$ \pm 100 for the fault gouge along active faults, as shown in Fig. $12 \mathrm{a}$. Both the $N_{\text {CTM }}$ values and $N_{\text {CTM }}$ variations decrease as the fault rock becomes more heavily deformed and the main fault plane is approached.

The rock/protolith $\rho_{\mathrm{t}}$ ratio was $\sim 0.8 \pm 0.15$ for cataclasite and the fault gouge along inactive faults, and $0.7 \pm 0.1$ for the fault gouge along active faults, as shown in Fig. $12 \mathrm{~b}$. The $\rho_{\mathrm{t}}$ ratio decreases as the fault rock becomes more heavily deformed and the main fault plane is approached, whereas the variation in the $\rho_{\mathrm{t}}$ ratio is approximately constant. Furthermore, the $\rho_{\mathrm{t}}$ ratio differences among the different rock types are smaller than the $N_{\text {CTM }}$ differences. 


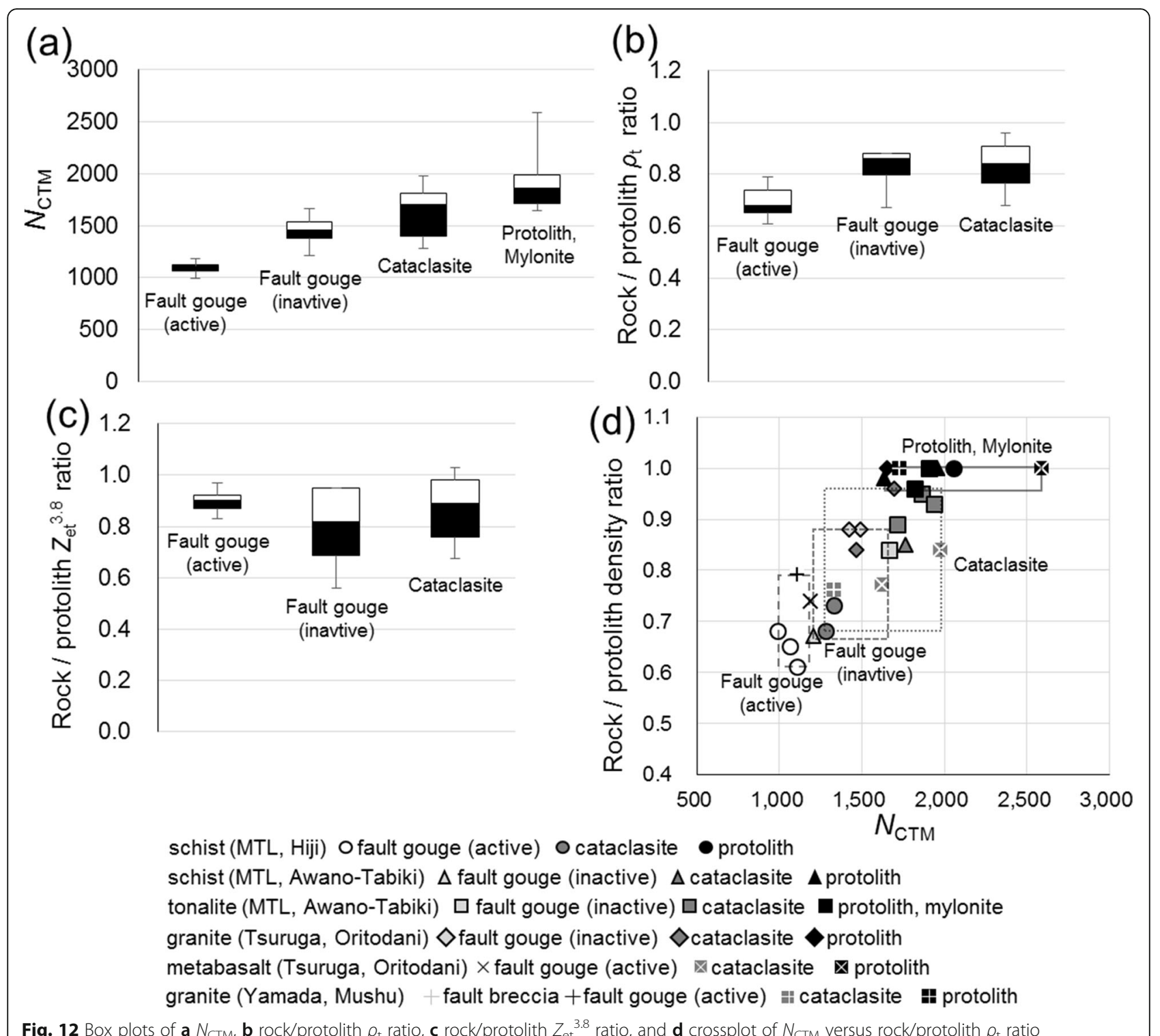

The rock/protolith $Z_{\text {et }}$ ratio was $\sim 0.85$, with no major difference between the analyzed fault rock types, as shown in Fig. 12c. Therefore, $Z_{\mathrm{et}}$ is not closely related to the fault rock types, which indicates that any distinct characteristics are dependent on differences in the protolith type (Fig. 5c).

This study demonstrates that analysis of the $N_{\text {CTM }}$ values in $\mathrm{CT}$ images provides the best proxy for detecting changes in fault rocks characteristics as the youngest active domain of a fault zone is approached. Furthermore, the $\rho_{\mathrm{t}}$ ratio of the active fault is smaller than those of other fault rocks, and the $Z_{\text {et }}$ ratio decreases by $\sim 15 \%$, regardless of the protolith type. This occurs because $N_{\text {СТM }}$, which is a function of both $\rho$ and $Z_{\mathrm{e}}$, is affected by both the changes in $\rho$ (dependent on the fault rock type) and decreases in
$Z_{\mathrm{e}}$. This is also due to how $N_{\text {СтM }}$ and the rock/protolith ratios are calculated: $N_{\text {СTM }}$ is calculated from more than 12,000 pixels of data by eliminating the sample area due to the influence of cracks or minerals with a large effective atomic number, with the rock/protolith $\rho_{\mathrm{t}}$ and $Z_{\mathrm{et}}$ ratios also calculated using only a portion of each sample area.

The $N_{\mathrm{CTM}}-$ rock/protolith $\rho_{\mathrm{t}}$ ratio relationship is shown in Fig. 12d. Both $N_{\text {СтM }}$ and the rock/protolith $\rho_{\mathrm{t}}$ ratio decrease as the main fault plane is approached and/or the degree of fracturing increases. However, there is a significant overlap between the $N_{\text {СтM }}-\rho_{\text {t }}$ ratio distribution areas for the fault gouge along the inactive fault and cataclasite, making it difficult to classify them using $N_{\text {СтM }}$ and the $\rho_{\mathrm{t}}$ ratio. This is due to the porosity increase, $N_{\text {СтM }}$ 
decrease, and rock/protolith $\rho_{\mathrm{t}}$ ratio decrease of the cataclasite adjacent to the fault gouge along active faults (HJ8-1, HJ8-5, T-3-4, YDA-4), which indicate that the fault activity affected the cataclasite at shallow depth.

\subsection{The lowest density domain and youngest active domain relationships in major fault zones}

The lowest $N_{\text {СтM }}$ value for each analyzed fault is at the fault gouge (HJ8-3, AT-2, T-3-3, and YDA-3), which is in contact with the latest main fault plane $Y$, and the rock/protolith $\rho_{\mathrm{t}}$ ratio is also the lowest at or near fault plane $Y$; these low values are due to the fact that the depth at which these samples are affected by the youngest fault activity is the shallowest at/near the active fault plane. Therefore, the lowest density domain of a fault may correspond to the youngest active domain of each fault, and the youngest active domain may be estimated using the $N_{\text {CTM }}$, which is a function of the density and effective atomic number. However, it should be noted that the lowest density region of a fault may not necessarily correspond to the youngest active domain of the fault because the density reduction of fault rocks may result from shear damage due to the fault activity, as well as the formation of secondary minerals due to mineral precipitation, phase transition, dissolution into groundwater, and other mechanisms. The possibility that the lowest density domain identified by the $N_{\text {СтM }}$ corresponds to the youngest active domain should be carefully examined in conjunction with detailed outcrop and microstructural observations to confirm the presence of lineations and composite planar fabric in the fault gouge due to shearing. Outcrop observations of each fault gouge from the youngest active domain identified in the four analyzed faults highlighted lineations and composite planar fabric due to shearing and possessed the lowest density domain identified by the $N_{\text {CTM }}$. Therefore, the four faults in this study can be classified as cases in which the lowest density domain corresponds to the youngest active domain of fault activity.

It may therefore be possible to recognize the youngest active domain of a fault zone via a joint analysis of the lowest density domain identified by the $N_{\text {СтM }}$, and fault outcrop and fault gouge microstructure observations. It is expected that the accuracy of the $\rho_{\mathrm{t}}$ and $Z_{\mathrm{et}}$ values obtained from the CT values in the fault fracture zone will be further enhanced as more studies conduct CT analyses on both active and inactive faults, and a greater diversity of protoliths.

\section{Conclusions}

This study considered fault rock and protolith samples that were derived from pelitic schist, tonalite, metabasalt, and granite along active faults (MTL, and Tsuruga and
Yamada faults) and an inactive fault (MTL). The density, porosity, and effective atomic number were determined for the different fault and protolith types, and relationships among the CT value, density, and effective atomic number were investigated. Our major findings and conclusions are as follows.

(1) The fault rock density, $\rho_{t}$, decreases as it approaches the youngest active fault plane, and the porosity, $\phi$, tends to increase by $\sim 24 \%$ as $\rho_{\mathrm{t}}$ decreases by $1 \mathrm{~g} / \mathrm{cm}^{3}$, regardless of the fault rock or protolith type. The porosity of the cataclasite adjacent to the fault gouge along the active faults is $19.7 \%$, which is significantly larger than those of the other cataclasite sample locations; this increased porosity may be due to the shallow depth that is affected by this proximal fault activity.

(2) The mean $\phi$ values are $1.5 \%$ (SD $=1.0 \%$ ) for the protoliths, $12.6 \%$ (SD $=6.9 \%$ ) for cataclasite, $12.0 \%$ $(\mathrm{SD}=4.8 \%)$ for the fault gouge along the inactive fault, $17.4 \%$ (SD $=4.6 \%$ ) for the fault gouge along the active faults, and $32.2 \%$ for the fault breccia.

(3) There is a positive correlation between $\rho_{t}$ and the effective atomic number, $Z_{\mathrm{e}}$, which is unique to each fault and protolith type.

(4) The modal CT number, $N_{\text {CTM }}$, which is calculated from a 2D CT image (excluding the periphery where $\mathrm{BH}$ is significant, and the influences of cracks and minerals with a large effective atomic number) can be used to estimate the $\rho_{\mathrm{t}}$ and $Z_{\mathrm{et}}$ values of the protolith and fault rock samples.

(5) The $N_{\text {CTM }}$ values were $\sim 1900 \pm 300$ for the protolith, $\sim 1650 \pm 250$ for cataclasite, $\sim 1450 \pm$ 200 for fault gouge in the inactive fault, and $\sim 1100$ \pm 100 for fault gouge in the active faults. Both $N_{\text {СTM }}$ and the variation in $N_{\text {СTM }}$ decreased near the main fault plane. The $N_{\text {СтM }}$ of the fault rock in each fault is the lowest in the fault gouge from the youngest active domain.

(6) The rock/protolith density ratio was $\sim 0.8 \pm 0.15$ for cataclasite and fault gouge along the inactive fault and $\sim 0.7 \pm 0.1$ for fault gouge along the active faults.

(7) The change in fault rock characteristics due to the transition to the youngest active domain of the fault zone is more distinct when analyzing $N_{\mathrm{CTM}}$, which is a function of the $\rho_{\mathrm{t}}$ and $Z_{\mathrm{e}}$, than the rock/ protolith $\left(\rho_{\mathrm{t}}\right.$ and $\left.Z_{\mathrm{et}}\right)$ ratios.

(8) The $N_{\text {CTM }}$ can be used to identify the lowest density domain of a fault.

(9) It may be possible to recognize the youngest active domain in major fault zones via a joint analysis of the lowest density domain identified using the $N_{\text {CTM }}$ and fault outcrop and fault gouge microstructure observations. 


\section{Acknowledgements}

We thank Seiji Matayoshi and Yasuhiro Yamada for their assistance with the analyses at CRIEPI. We are grateful to Tadahiro Nishizaki for his assistance during the sample collection in the field. Kana Tanabe, Shotaro Yamamoto, Kozo Kiyose, Koichi Hojo, and Koudai Kuramoto provided careful guidance during the X-ray effective energy measurements and CT imaging. Two anonymous reviewers provided valuable suggestions in adding discussion of the relationship between the lowest density domain and the youngest active domain in major fault zones, which greatly improved this paper.

\section{Authors' contributions}

Al proposed this study and performed compilation and interpretation on all analysis results. HT provided support and guidance for all analyzes and interpretation of analysis results. NA captured CT images and performed XRF analysis. TS took the lead in sampling of fault rocks. EN, SN, and KU collaborated with the corresponding author to interpret analysis results. All authors read and approved the final manuscript.

\section{Funding}

This work was funded by Kansai Electric Power Co. Inc.

\section{Availability of data and materials}

Data sharing not applicable to this article as no datasets were generated now. Please contact author for data requests.

\section{Declarations}

\section{Competing interests}

The authors of this article declare that they have no competing interests.

\section{Author details}

'Kansai Electric Power Co. Inc., 3-6-16, Nakanoshima, Kita-ku, Osaka 530-8270, Japan. ${ }^{2}$ School of Creative Science and Engineering, Waseda University, 1-6-1, Nishiwaseda, Shinjuku-ku, Tokyo 169-8050, Japan. ${ }^{3}$ Faculty of Education and Integrated Arts and Sciences, Waseda University, 1-6-1, Nishiwaseda, Shinjuku-ku, Tokyo 169-8050, Japan. ${ }^{4}$ Dia Consultants Co. Ltd., 5-3, Toyotsu-cho, Suita-shi, Osaka 564-0051, Japan. ${ }^{5}$ Central Research Institute of Electric Power Industry, 1646 Abiko, Abiko-shi, Chiba 270-1194, Japan.

Received: 18 March 2021 Accepted: 15 July 2021

Published online: 30 September 2021

\section{References}

Aiyama K, Tanaka S, Sasaki T (2017) Consideration of the activity of a fault based on detailed structural analysis of a fault fracture zone: case study of the Yamada Fault, Western Japan. J Japan Soc Eng Geol 58(1):2-18

Boespflug X, Long BFN, Occhietti S (1995) CAT-scan in marine stratigraphy: a quantitative approach. Marine Geol. 122(4):281-301. https://doi.org/10.1016/ 0025-3227(94)00129-9

Earthquake Research Committee (2004) Long-term evaluation of the Yamada Fault Zone. The Headquarters for Earthquake Research Promotion. https:// www.jishin.go.jp/main/chousa/katsudansou_pdf/74_yamada.pdf/*

Geet MV, Swennen R, Wevers M (2000) Quantitative analysis of reservoir rocks by microfocus X-ray computerized tomography. Sedimentary Geol. 132(1-2):2536. https://doi.org/10.1016/S0037-0738(99)00127-X

Hirono T, Sakaguchi M, Otsuki K, Sone H, Fujimoto K, Mishima T, Lin W, Tanikawa W, Tanimizu M, Soh W, Yeh E, Song S (2008) Characterization of slip zone with the 1999 Taiwan Chi-Chi earthquake: X-ray CT image analyses and microstructural observation of the Taiwan Chelungpu fault. Tectonophysics 449:63-84

Hounsfield GN (1973) Computerized transverse axial scanning (tomography): Part I. Description of system. Br J Radiol 46(552):1016-1022. https://doi.org/10.12 59/0007-1285-46-552-1016

Hubbell JH (1982) Photon mass attenuation and energy-absorption coefficients from I keV to $20 \mathrm{MeV}$. Int. J Appl Radiat Isot. 33(11):1269-1290. https://doi. org/10.1016/0020-708X(82)90248-4

Ikeda R, Omura K, lio Y, Arai T, Kobayashi K, Matsuda T, Shimada K, Tanaka H, Tomita T, Hirano S (2001) Drilling investigation through the Nojima Fault of the 1995 Hyogo-ken Nanbu Earthquake, Japan. National Res Ins Earth Sci Disaster Prev Res Rep 61:141-153
Iwamori A, Sasaki T, Sugimori T, Aiyama K, Goto N, Yanagida M, Shigemitsu Y, Tanaka Y (2015) Activity history of the Yamada fault in the late Quaternaryoutcrop survey at Mushu, Tanto-cho. Proceedings of the 2015 Autumn Meeting of the Active Fault Society of Japan, pp 62-63

Iwamori A, Takagi H, Asahi N, Sugimori T, Nakata E, Nohara S, Ueta K (2020) Development of a method for presuming the density and effective atomic number of mineral samples by utilizing medical X-ray CT scanning. Jap Mag Mineral Petrol Sci 49:101-117

Ketchman RA, Carlson WD (2001) Acquisition, optimization and interpretation of $X$-ray computed tomographic imagery: applications to the geosciences. Comp Geosci. 27(4):381-400. https://doi.org/10.1016/S0098-3004(00)00116-3

Ketchman RA, Hanna RD (2014) Beam hardening correction for X-ray computed tomography of heterogeneous natural materials. Comp Geosci. 67:49-61. https://doi.org/10.1016/j.cageo.2014.03.003

Kurimoto C, Naito K, Sugiyama Y, Nakae S (1999) Geological map of Japan 1: 50,000, Tsuruga, National Institute of Advanced Industrial Science and Technology

Kuroda K (1968) Geological map of Japan 1: 200,000. Miyazu, National Institute of Advanced Industrial Science and Technology

Mizoguchi K, Ueta K (2012) Evaluation of fault activity based on fault-zone properties - Microfracture analysis of damage zone along an active fault located east of epicentral area of the 1943 Tottori Earthquake, Japan. Civil Engin Res Lab Rep No. N11041:17

Morrow CA, Lockner DA (2001) Hayward fault rocks: Porosity, density and strength measurements. U.S. Department of the Interior, USGS Open-File Report 2001-421

Nakano T, Nakashima Y, Nakamura K, Ikeda S (2000) Observation and analysis of internal structure of rock using X-ray CT. J Geol Soc 106:363-378

National Institute of Advanced Industrial Science and Technology (2016) 151 Tsuruga earthquake fault. Active fault database of Japan. https://gbank.gsj. jp/activefault/

Nishioka Y, Nakae S, Takeuchi K, Banno Y, Mizuno K, Ozaki M, Nakashima R, Sanematsu K, Nawa K, Komazawa M (2010) Geological map of Japan 1: 200,000, Ise, National Institute of Advanced Industrial Science and Technology

Nishizawa O, Nakano T, Noro H, Inazaki T (1995) Recent advances of X-ray CT technology for analyzing geologic materials. Bull Geol Surv 46:565-571

Okada A (1992) Proposal of the segmentation on the Median Tectonic Line active fault system.Mem. Geol Soc 40:15-30

Orsi TH, Edwards CM, Anderson AL (1994) X-ray computed tomography: a nondestructive method for quantitative analysis of sediment cores. J Sed Res A64:690-693

Ozaki M, Makimoto H, Sugiyama Y, Mimura K, Sakai A, Kubo K, Kato H, Komazawa M, Hiroshima T, Sudo S (2002) Geological map of Japan 1: 200,000. Kofu, National Institute of Advanced Industrial Science and Technology

Raynaud S, Fabre D, Mezerolle F, Geraud Y, Latiere HJ (1989) Analysis of the internal structure of rocks and characterization of mechanical deformation by a non-destructive method: X-ray tomodensitometry. Tectonophysics. 159(12):149-159. https://doi.org/10.1016/0040-1951(89)90176-5

Rempe M, Mitchell T, Renner J, Nippress S, Ben-Zion Y, Rockwell T (2013) Damage and seismic velocity structure of pulverized rocks near the San Andreas Fault. J Geophys Res Solid Earth 118(6):2813-2831. https://doi.org/10.1002/jgrb.50184

Shigematsu N, Kametaka M, Inada N, Miyawaki M, Miyakawa A, Kameda J, Togo T, Fujimoto K (2017) Evolution of the Median Tectonic Line fault zone, SW Japan, during exhumation. Tectonophysics. 696-697:52-69

Takagi H (1984) Mylonitic rocks along the Median Tectonic Line in TakatoIchinose area, Nagano Prefecture. J Geol Soc 90:81-100

Takagi H (1985) Mylonitic rocks of the Ryoke belt in the Kayumi area, eastern part of the Kii Peninsula. J Geol Soc 91:637-651

Takagi H, Kobayashi K (1996) Composite planar fabrics of fault gouges and mylonites-comparative petrofabrics. J Geol Soc 102:170-179

Takagi H, Sugiyama K, Tamura I, Mizuno K, Kitazawa N, Kawamoto K (2019) Identification of the youngest activity of the Median Tectonic Line at Hiji outcrop, Ina City, Nagano Prefecture. Active Fault Res 50:1-12

Takeuchi F, Nakamura K, Matsumura K, Watanabe K (2005) Density of stones observed near and around the Yamazaki Fault System. Annu Disas Prev Res Inst Kyoto Univ 48B

Tanaka Y, Kametaka M, Okazaki K, Suzuki K, Seshimo K, Aoki K, Shimada K, Watanabe T, Nakayama K (2018) Examination of Evaluation Method for Fault Activity Based on Morphological Observation of Fault Planes. J Japan Soc Eng Geol 59(1):13-27 
The Japanese Geotechnical Society (2017) Japanese Geotechnical Society Standards Vol. 2-Laboratory Testing Standards of Geomaterials, p 300

Tsuchiyama A, Uesugi K, Nakano T (2000) A study of three-dimensional structures of rocks and minerals using a high-resolution $\mathrm{X}$-ray $\mathrm{CT}$ method-primitive materials in the solar system and chondrules. J Geogr (Chigaku Zasshi) 109: $845-858$

Ueta K, Tani K, Kato T (2000) Computerized X-ray tomography analysis of threedimensional fault geometries in basement-induced wrench faulting. J Eng Geol 56(1-2):197-210. https://doi.org/10.1016/S0013-7952(99)00143-X

Verhelst F, David P, Fermont W, Jegers L, Vervoort A (1996) Correlation of 3Dcomputerized tomographic scans and 2D-colour image analysis of Westphalian coal by means of multivariate statistics. Int J Coal Geol. 29(1-3): 1-21. https://doi.org/10.1016/0166-5162(95)00026-7

Wakita K, Harayama S, Kano K, Mimura K, Sakamoto T, Hitoshima T, Komazawa M (1992) Geological map of Japan 1: 200,000. Gifu, National Institute of Advanced Industrial Science and Technology

Wellington SL, Vinegar HJ (1987) X-ray computerized tomography. J Petrol Tech. 39(08):885-898. https://doi.org/10.2118/16983-PA

Zhang F, An M, Zhang L, Fang Y, Elsworth D (2020) Effect of mineralogy on friction-dilation relationships for simulated faults: implications for permeability evolution in caprock faults. Geosci Front 11(2):439-450. https:// doi.org/10.1016/j.gsf.2019.05.014

\section{Publisher's Note}

Springer Nature remains neutral with regard to jurisdictional claims in published maps and institutional affiliations.

\section{Submit your manuscript to a SpringerOpen ${ }^{\circ}$ journal and benefit from:}

- Convenient online submission

- Rigorous peer review

- Open access: articles freely available online

- High visibility within the field

- Retaining the copyright to your article

Submit your next manuscript at $\boldsymbol{\nabla}$ springeropen.com 